\title{
Analysis of miscellaneous non-ambergris organic jetsam beach deposits
}

\author{
Paul A. Sutton and Steven J. Rowland ${ }^{\star}$
}

Petroleum \& Environmental Geochemistry Group, Biogeochemistry Research Centre, University of Plymouth, Drake Circus, Plymouth, PL4 8AA, Devon, U.K.

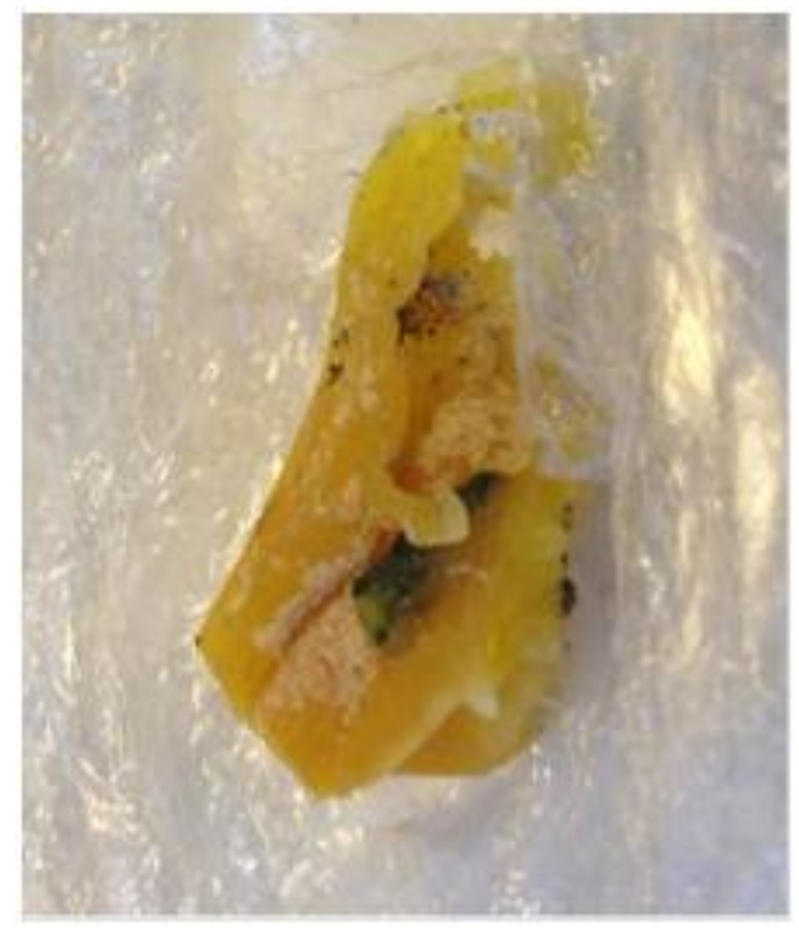

*To whom correspondence should be addressed. 


\section{Introduction}

In 2013, we, along with colleagues, were successful in identifying a mystery pollutant as polyisobutylene (PIB), which was responsible for the death of thousands of seabirds (BBC 2013a-c). The results of those analyses will be reported elsewhere.

However, as a result of the accompanying media attention and publicity, over the following years we began to receive samples of miscellaneous organic substances found on beaches worldwide by members of the public. In several instances the finders suggested (and hoped that) the material might be ambergris. This led us to develop methods for the routine identification of ambergris. Analytical results for samples of jetsam positively identified as ambergris by the methods we developed have been reported in those publications (e.g. Rowland and Sutton, 2017).

In the present communication we describe the results of analyses of jetsam samples which proved not to be ambergris. We hope that the data may act as a guide to others for the successful identification of organic jetsam samples.

Rather than separate the reports of these studies into conventional sections of Materials, Results etc, we report the results of each case study in turn, with a short conclusion (shown in bold type), to each case study..

Details of conventional analytical methods such as Fourier transform infrared spectroscopy (FTIR), gas chromatography (GC), high temperature GC (HTGC), GC-mass spectrometry (GC-MS), HTGC-MS and derivatisation, can all be found in our previous publications (e.g. Sutton and Rowland 2012; Rowland and Sutton, 2017).

\section{Analysis of an unknown beach deposit from Bude, Cornwall, U.K. on $11^{\text {th }}$ September 2013}

A sub-sample from a yellowy-white beach deposit (approx. size of whole deposit $500 \mathrm{~mm} \mathrm{x}$ $250 \mathrm{~mm} \times 100 \mathrm{~mm}$ ) which had a hydrocarbon odour, was submitted to our laboratory by local authorities on $11^{\text {th }}$ September 2013 in order to ascertain whether it was ambergris. An aliquot $(4.1 \mathrm{mg})$ was taken from the white part of the sub-sample and derivatised with BSTFA $1 \%$ TMCS before the sample was diluted to $1 \mathrm{mg} / \mathrm{mL}$ and analysed using HTGC 
(Figure 1). After cooling the derivatised sample, a white solid was produced reminiscent of wax, so the sample was analysed using hot injection HTGC. Comparison of the high temperature gas chromatograms of the sample with those of an $n$-alkane standard $\left(C_{10-30}\right.$, 40,50 and 60 ) showed that the peaks in the sample precisely matched those of several of the nalkanes, with a distribution ranging from around $n \mathrm{C}_{18}-n \mathrm{C}_{37}$, with a distribution maximum at $n \mathrm{C}_{25}$. There was an unresolved complex mixture underlying the $n$-alkane series and two series of peaks (assumed to be due to two homologous series) eluting between the $n$ alkanes (Figure 2).

This sample had characteristics typical of a petroleum fraction and appeared to be a 'wax ball'.

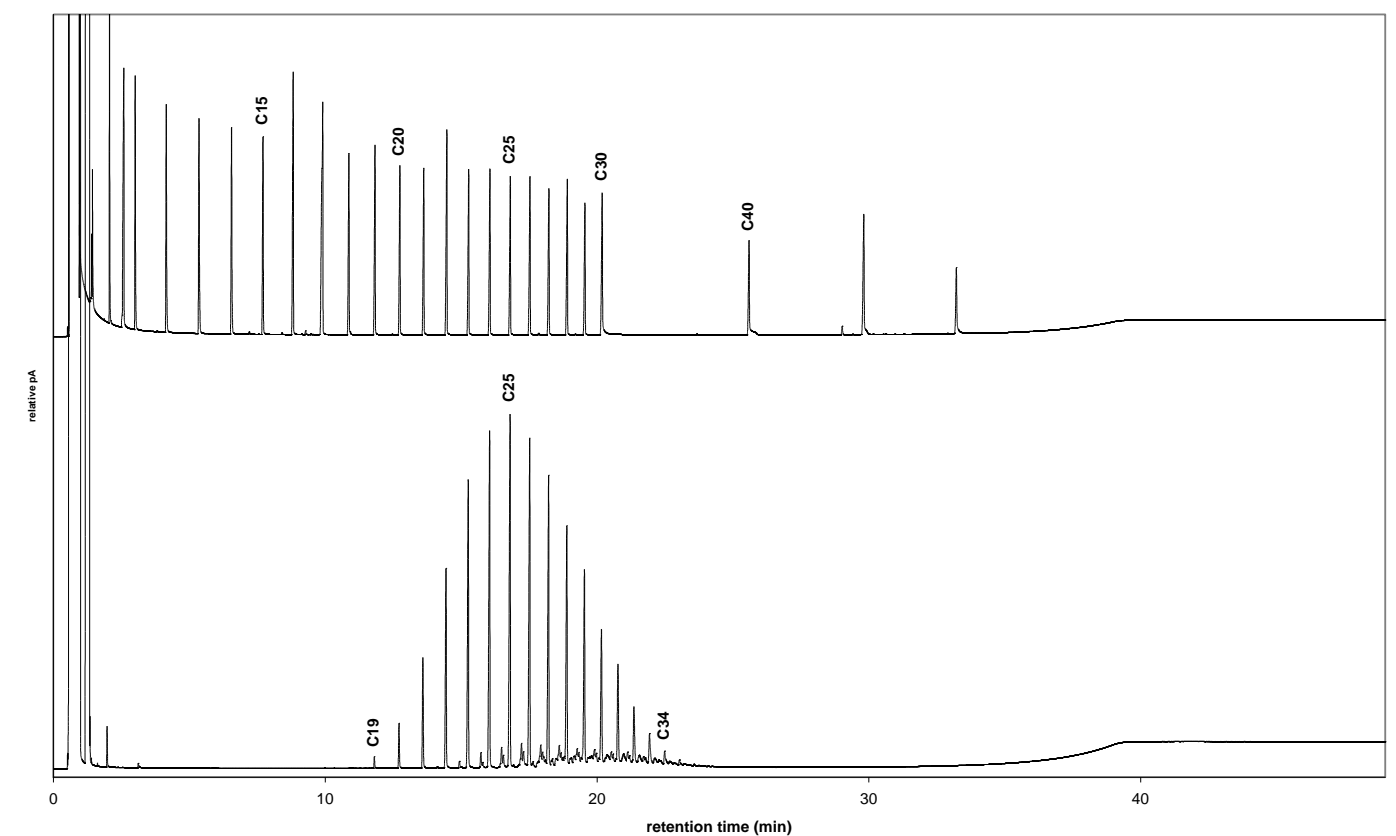

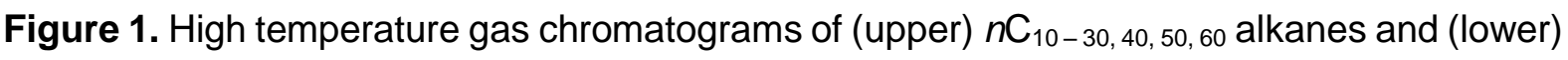
extract from Bude beach deposit (TMS; $1 \mathrm{mg} / \mathrm{mL} ; 0.5 \mu \mathrm{L}$ hot injection). 


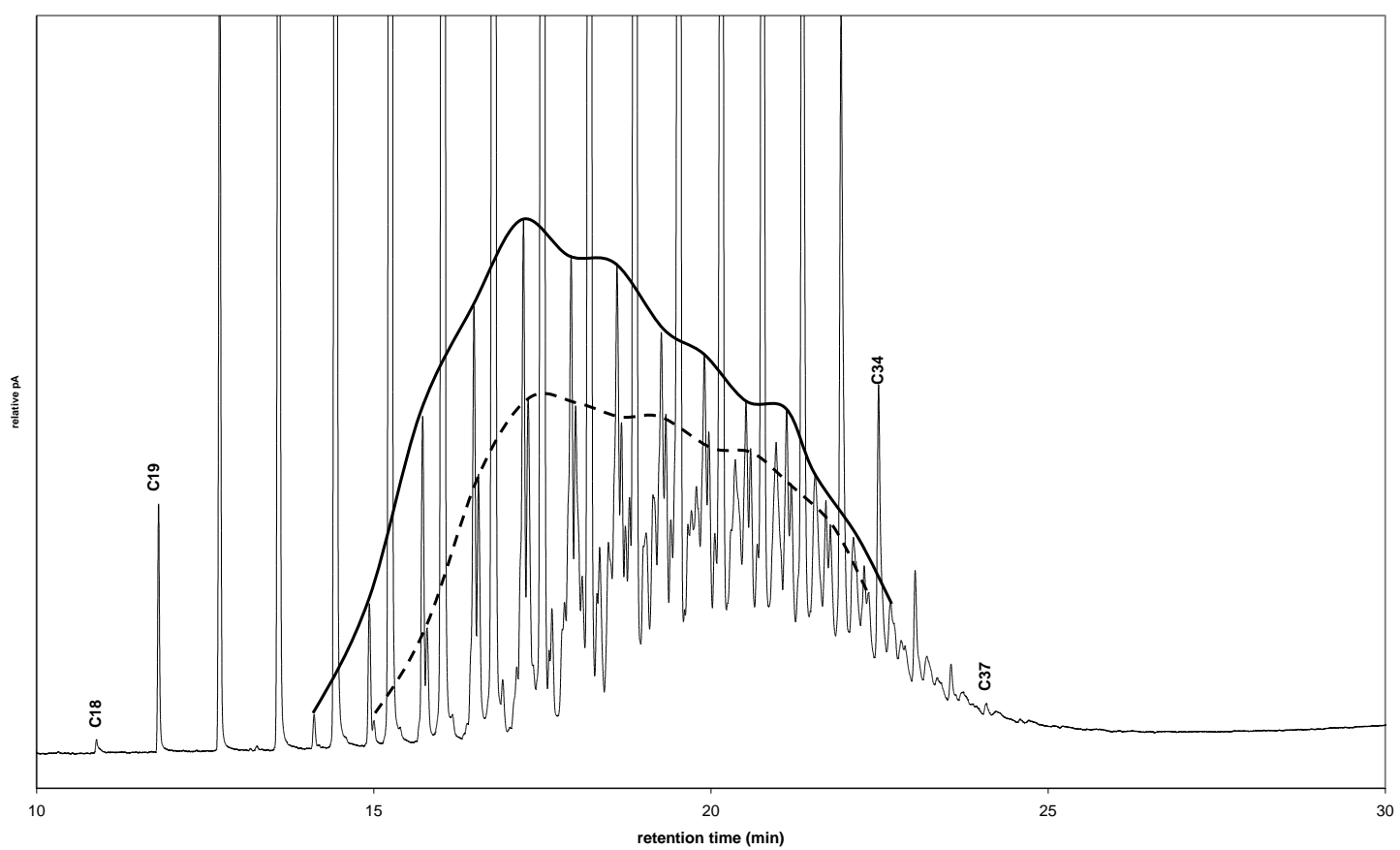

Figure 2. Zoomed region high temperature gas chromatogram of extract from Bude beach deposit (TMS; $1 \mathrm{mg} / \mathrm{mL} ; 0.5 \mu \mathrm{L}$ hot inj.). Two homologous series between $n$-alkanes highlighted in black full and dashed lines.

\section{Analysis of mystery substance from Praa Beach, Cornwall, U.K. on $\mathbf{2 4}^{\text {th }}$} October 2013

A sample of 'mystery' substance was supplied to our laboratory from Mr David George (BBC Southwest) on the $24^{\text {th }}$ October 2013. The sample had a distinct pungent odour and appeared to be a greasy, soft, white semi-solid with a consistency not unlike soft margarine (Figure 3). When rubbed between gloved fingers it appeared to melt to a clear liquid.
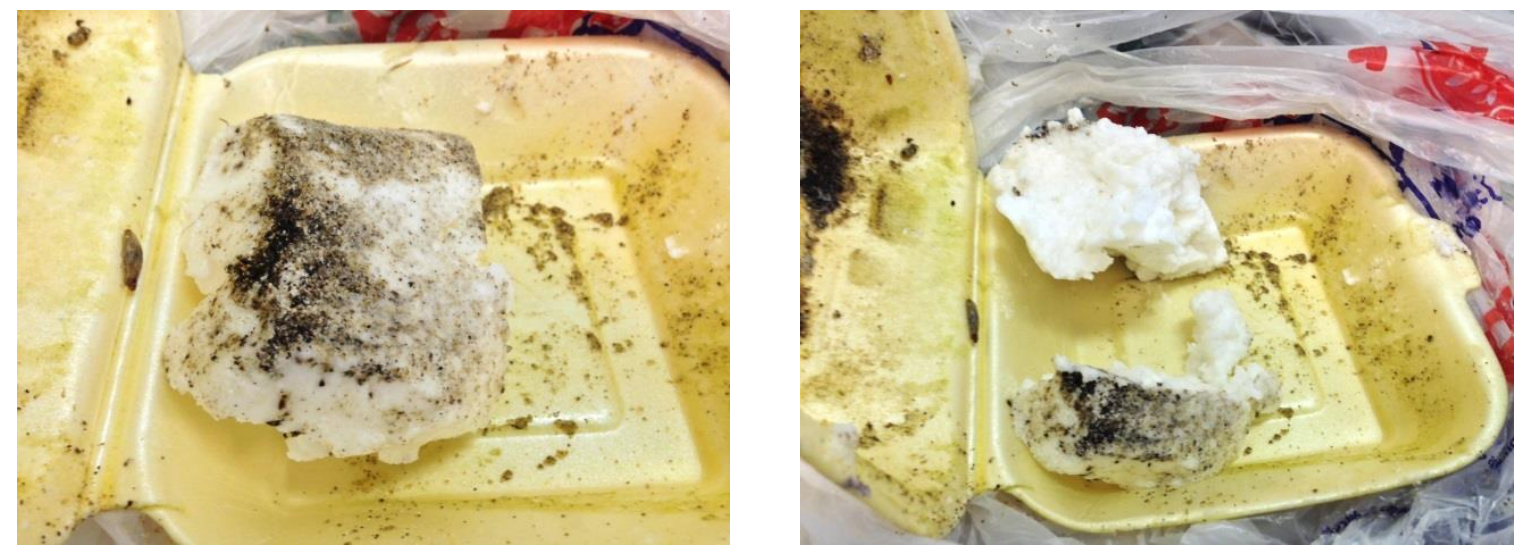

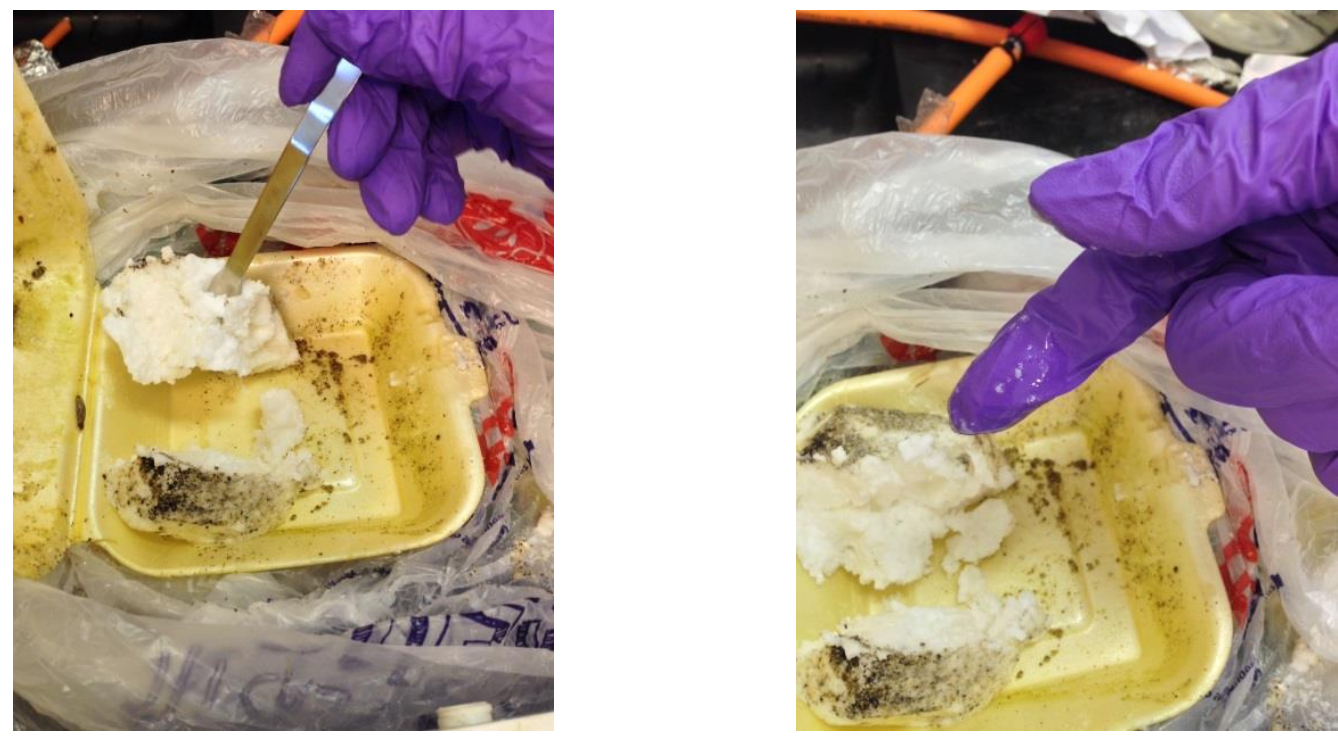

Figure 3. Photographs of 'mystery' substance from Praa beach as supplied

A sample was taken from the centre of the supplied deposit to avoid contamination from beach detritus. Two aliquots were weighed out with a clean spatula (PRAA A, $22.7 \mathrm{mg}$ and PRAA B, $38.6 \mathrm{mg}$ ). Sample A was diluted to $10 \mathrm{mg} / \mathrm{mL}$ with cyclohexane (required vortexing and appeared slightly cloudy), sample B to $10 \mathrm{mg} / \mathrm{mL}$ with dichloromethane (DCM; readily soluble, clear solution). These samples were analysed by FTIR with no obvious differences between the spectra, other than minor difference in intensity (Figure 4). An FTIR spectrum of palm oil was also obtained (Figure 5) and compared with the sample spectrum (Figure 6).

From the comparative spectra a number of different transmittances were obvious (e.g. 935, $\left.1277,1412,1711,2669,2948 \mathrm{~cm}^{-1}\right)$. In some instances these represented differences in relative intensity to those observed in palm oil, in other cases (e.g. $1711 \mathrm{~cm}^{-1}$, carboxylic acid) the transmittance peaks were not present in the palm oil spectrum. The ester band $\left(1743 \mathrm{~cm}^{-}\right.$ 1; Figure 2) was less intense than the carboxylic acid band $\left(1711 \mathrm{~cm}^{-1}\right.$; Figure 1$)$ indicating the quantitative importance of carboxylic acids in the beach sample. This suggested that the unknown sample was not simply palm oil and further analysis using HTGC was undertaken. 


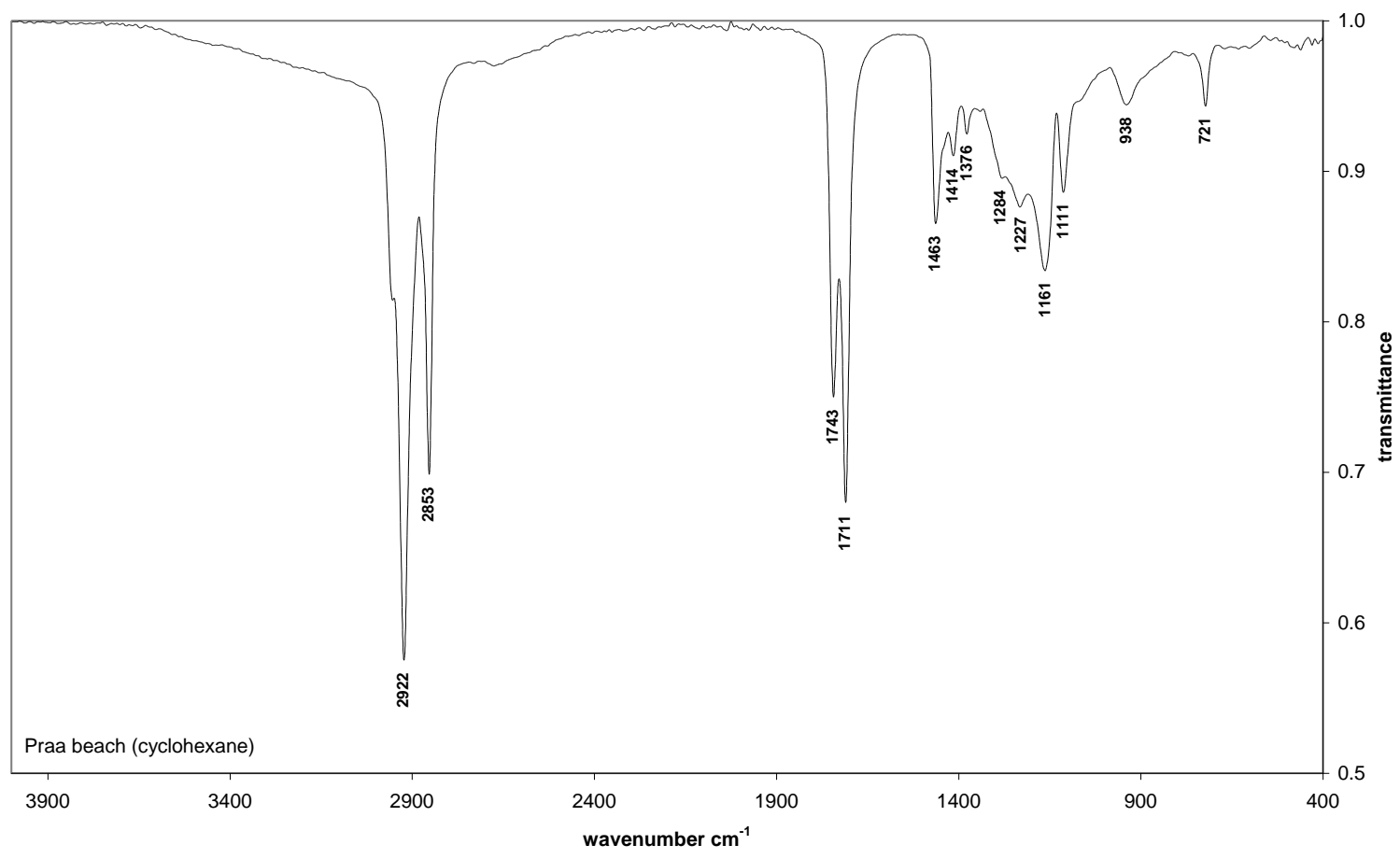

Figure 4. IR spectrum of mystery substance dissolved in cyclohexane (solvent allowed to evaporate before analysis)

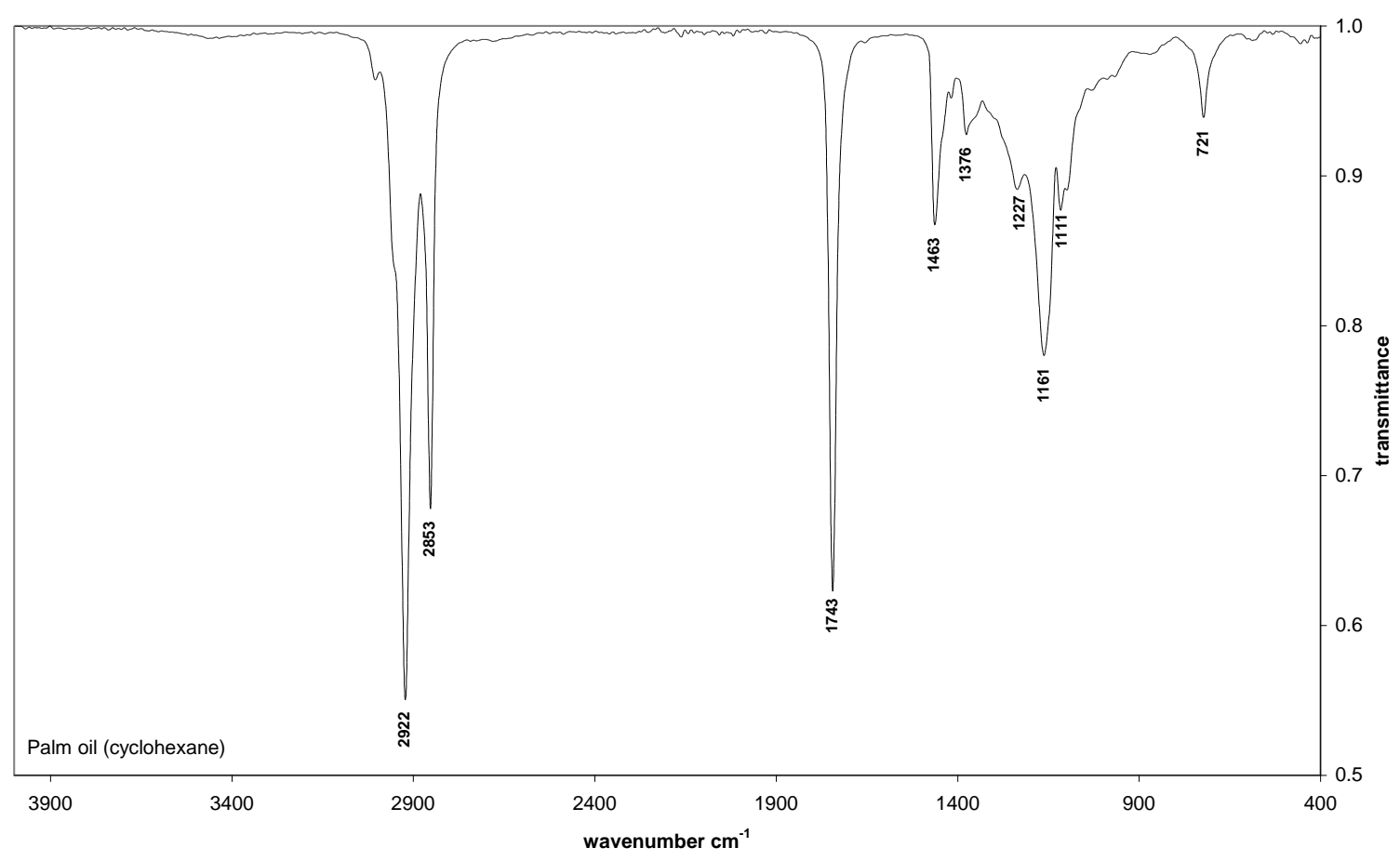

Figure 5. IR spectrum of palm oil 


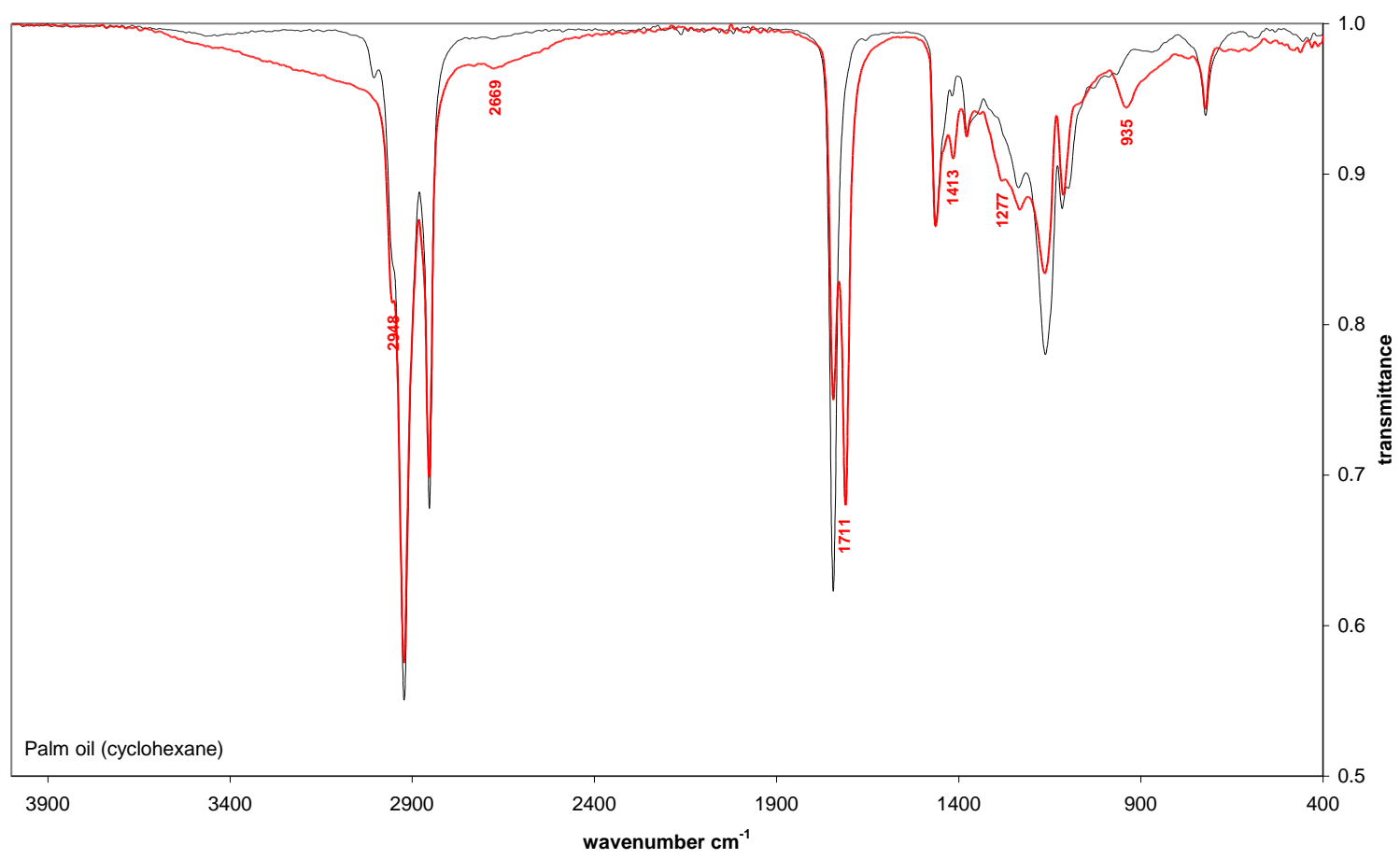

Figure 6. Comparison overlay of IR spectra of unknown and palm oil (key different bands noted in red)

A $100 \mu \mathrm{L}$ aliquot of sample B was taken and dried $\left(\mathrm{N}_{2} / 40^{\circ} \mathrm{C}\right)$ before derivatisation with BSTFA $1 \%$ TMCS (nom. $50 \mu \mathrm{L} ; 70^{\circ} \mathrm{C} ; 1 \mathrm{~h}$ ), cooling and dilution with $1 \mathrm{~mL}$ DCM for HTGC analysis (Figure 7). A BSTFA/TMCS blank was prepared in the same manner.

No peaks were detected in the chromatogram of the solvent blank (Figure 7a). Two small early eluting peaks were detected in the chromatogram of the derivatising agent procedural blank (Figure $7 \mathrm{~b}$ ) and could therefore be accounted for in sample chromatograms. Chromatograms of the underivatised (Figure 7c) and derivatised (Figure 7d) sample generally contained peaks with equivalent retention times. However, as would be expected for peaks of underivatised polar compounds, early eluting peaks ( $<10 \mathrm{~min}$ ) in Figure $7 \mathrm{c}$ had poor peak shape owing to significant interaction with the stationary phase. Following derivatisation, peak shape was improved and as a result the heights of these peaks also increased. Peaks eluting after 10 minutes were not affected by derivatisation. The peak profile and retention time of peaks with retention time from around 16 - 22 minutes suggested to us that they could be triacylglycerides, which are common constituents of vegetable oils as well as of some other substances. Peaks eluting between 10 - 16 minutes may be short chain triacylglycerides or other compounds. Integration of peak areas (assumed response factor 1 ) showed that peaks between $3.0-10.5$ minutes accounted for $57 \%$ of the total signal, peaks between $10.5-17.4$ minutes around $15 \%$ of total signal, and the presumed triacylglycerides (17.4 - 20.6 min) around $21 \%$ of the 
total signal. Given comments in the media that the sample was a type of palm oil, comparative HTGC analysis with palm oil was also undertaken.

At this point it was tentatively concluded that the sample contained polar compounds, probably carboxylic acids, consistent with the HTGC peak shapes ( $<10$ min retention times) and the IR data $\left(\mathrm{O}-\mathrm{H}\right.$ stretch of $\mathrm{COOH}$ groups, $\left.2669 \mathrm{~cm}^{-1}\right)$ and a series of triacylglycerides.

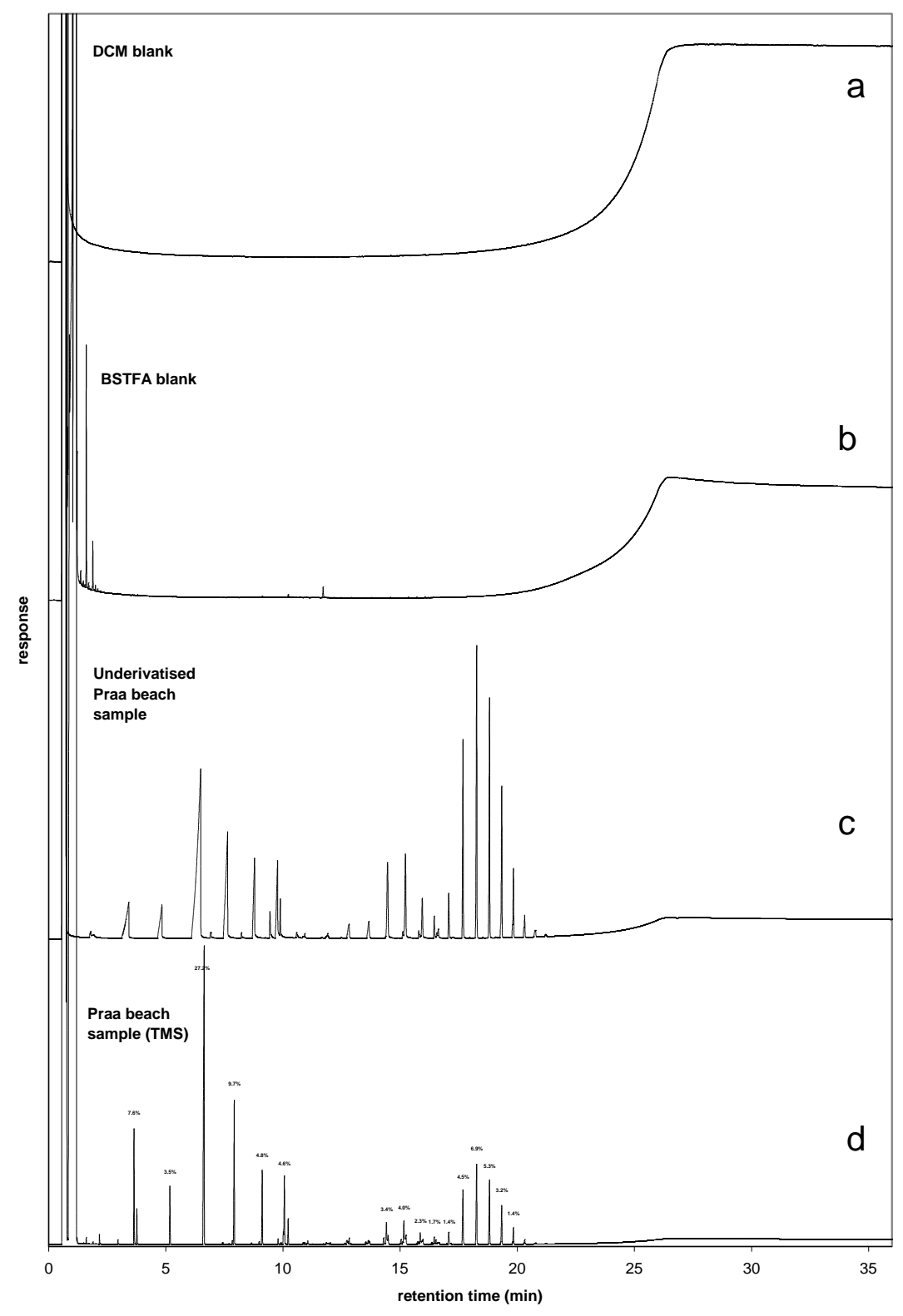

Figure 7. HTGC chromatograms of (a) DCM solvent blank, (b) BSTFA/TMCS procedural blank, (c) underivatised sample of Praa beach deposit, (d) trimethylsilylated sample Praa beach. 
A sample of palm oil (10 mg/mL in DCM) was prepared. An aliquot of the sample was derivatised with BSTFA/TMCS (to match the beach sample derivatisation) and diluted to 0.1 $\mathrm{mg} / \mathrm{ml}$ for HTGC and HTGC-MS analysis. Trimethylsilylated Praa beach deposit sample was diluted to $0.1 \mathrm{mg} / \mathrm{mL}$ for HTGC re-analysis and HTGC-MS analysis (Figure 8).

The retention times of major peaks in the palm oil sample (Figure 8a) did not match those in the Praa beach deposit sample (Figure $8 \mathrm{~b}$ ), which eluted at earlier retention times. The chromatogram of the palm oil sample was dominated by two major peaks representing $\mathrm{C}_{50}$ and $\mathrm{C}_{52}$ triacylglycerides, indicating that triacylglycerides in the Praa beach sample were somewhat shorter chain compounds. These samples were then analysed using HTGC-MS.

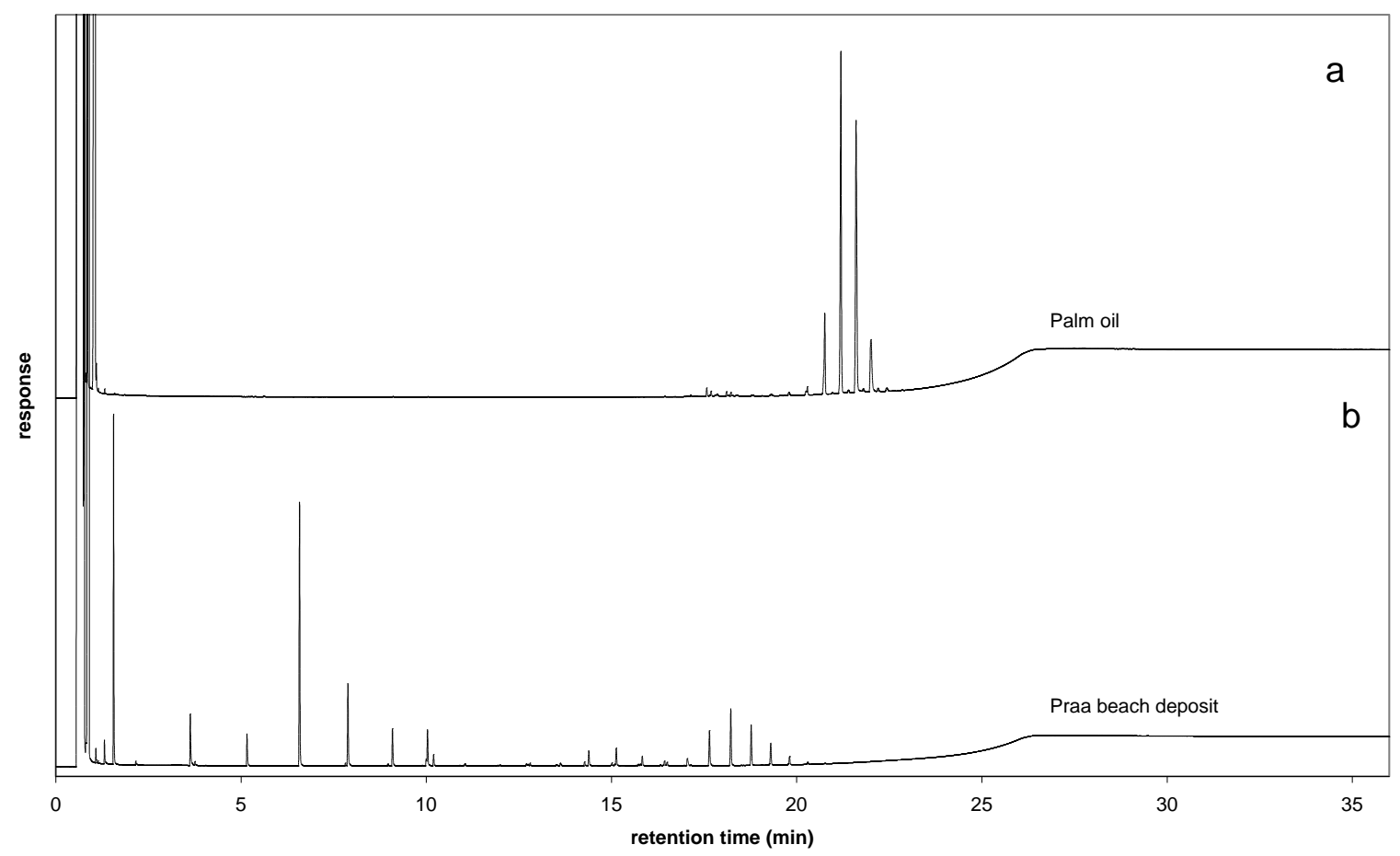

Figure 8. HTGC chromatograms of derivatised samples of (a) palm oil and (b) Praa beach deposit.

Samples were analysed using HTGC-MS and peak mass spectra searched against NIST MS v2.0 library, for presentation purposes matched spectral assignments were added to the HTGC chromatogram of the trimethylsilylated Praa beach deposit (Figure 9).

Using mass spectrometry a number of features of the chromatogram were tentatively identified. Peaks between 3.6 - 9.1 minutes were identified as a homologous series of $n$-alkanoic acids $\left(\mathrm{C}_{8}, \mathrm{C}_{10}, \mathrm{C}_{12}, \mathrm{C}_{14}, \mathrm{C}_{16}\right)$. Other identifications were more tentative: however, the match for lauric acid 2, 3-bis(trimethylsiloxy)propyl ester (RT $10.03 \mathrm{~min}$ ) indicated the presence of partially degraded triacylglycerides where two of the fatty acid chains have been 'lost'. Similarly, peaks 
between 17.06 - 20.31 minutes were likely to be triacylglycerides whose molecular ions were not detected. Peaks between 10.5 - 17.0 minutes were speculated to be degraded triacylglycerides, from which only one fatty chain had been 'lost'.

At this point it was concluded that the sample comprised a mixture of triacylglycerides and degraded triacylglycerides where one or two fatty chains had been 'lost'. $\mathrm{C}_{8-16 \text { (even numbered only) }}$ $n$-alkanoic acids were probably by-products of this degradation. If this assertion is correct then the fatty acid distribution of triglycerides should be represented by the fatty acids, i.e

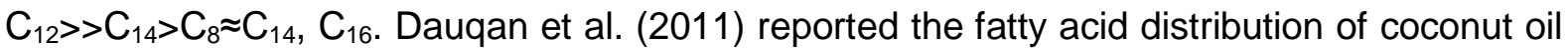
as: $\mathrm{C}_{12}(46 \%), \mathrm{C}_{14}(21 \%), \mathrm{C}_{16}(9 \%), \mathrm{C}_{18: 1}(7 \%), \mathrm{C}_{8}(6.6 \%), \mathrm{C}_{10}(5.1 \%), \mathrm{C}_{18}(2.9 \%), \mathrm{C}_{18: 2}(1.6 \%)$.

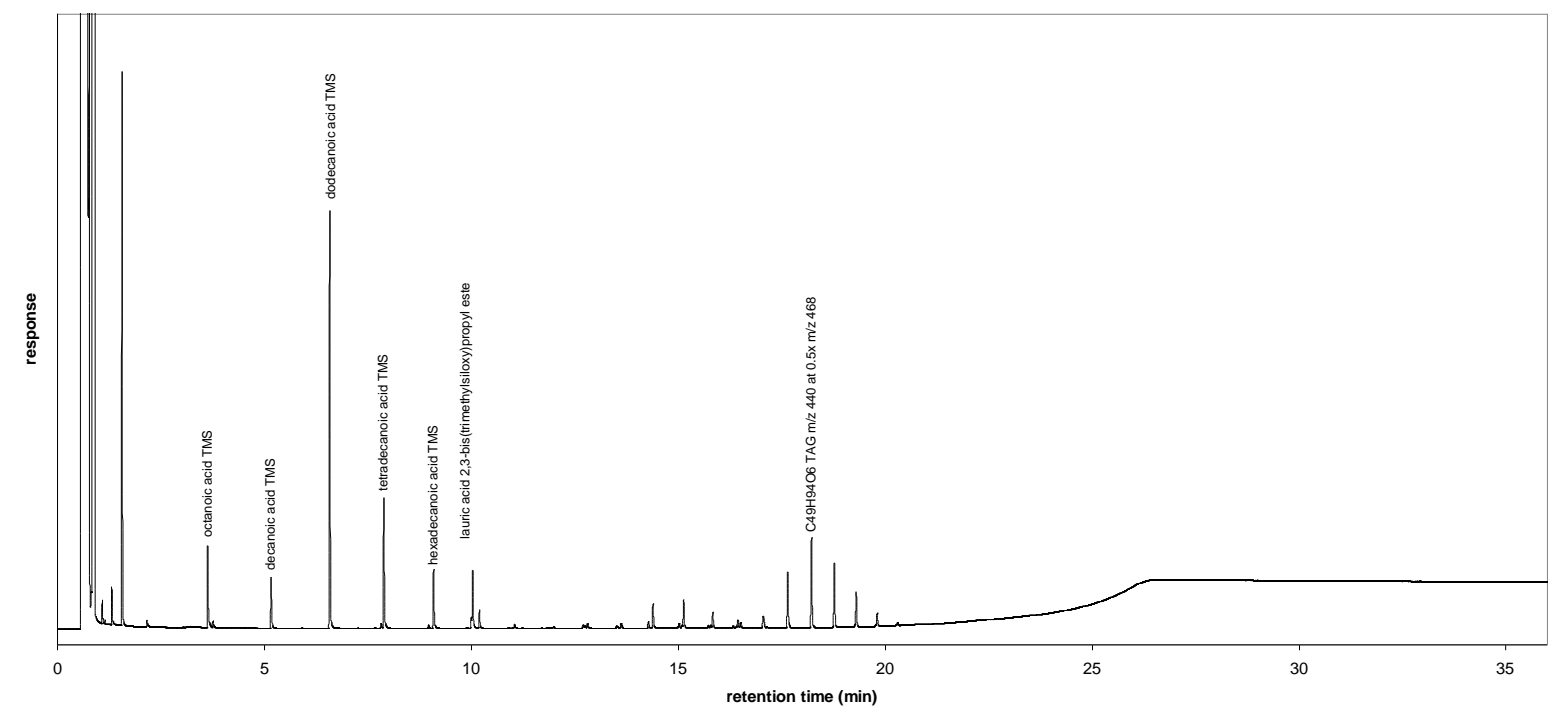

Figure 9. HTGC chromatogram with peak assignments from HTGC-MS analysis and library matching (NIST MS Search v2.0) mass spectra.

A sample of coconut oil was prepared $(0.5 \mathrm{mg} / \mathrm{mL})$ and compared to that of the Praa Beach deposit TMS sample (0.5 mg/mL; Figure 10). A coconut oil sample was also analysed using FTIR (Figure 11).

The distribution and relative intensity of triacylglycerides in coconut oil was different to that in the Praa beach deposit sample. The FTIR spectrum of coconut oil was almost identical to that of palm oil (Figure 5), with subtle minor differences in intensities, but different to that of the beach deposit sample. 


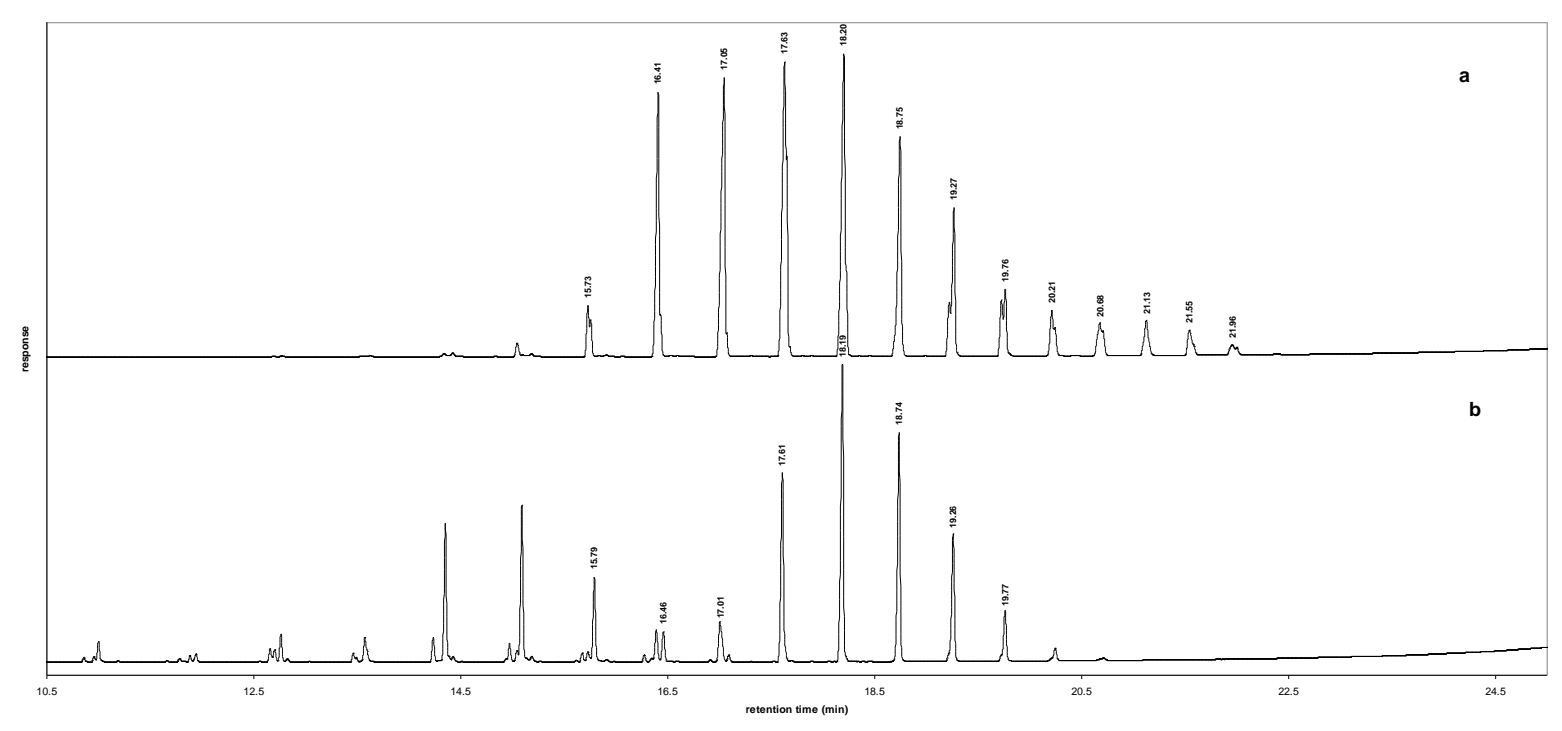

Figure 10. Partial HTGC chromatogram of (a) coconut oil, and (b) Praa beach deposit sample (TMS).

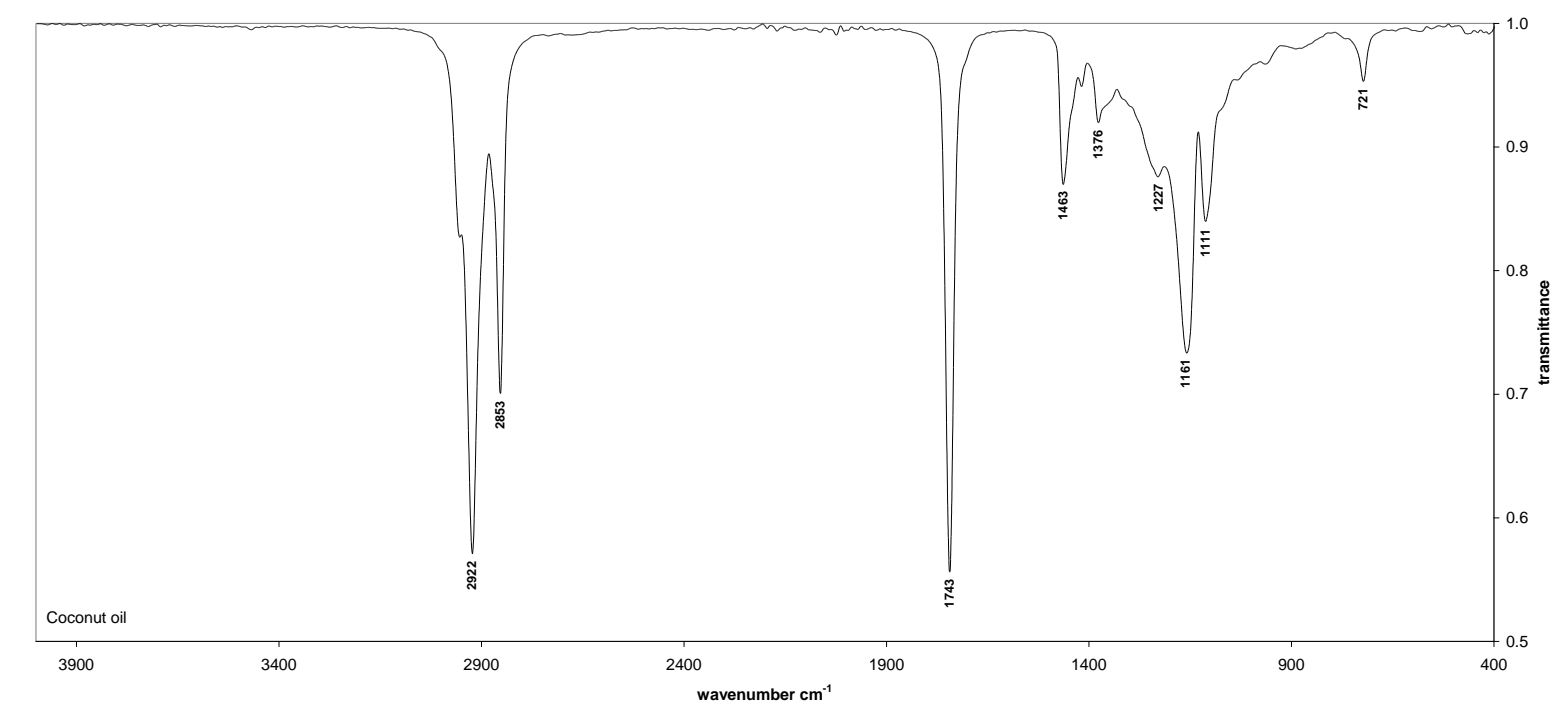

Figure 11. IR spectrum of coconut oil

It was also observed that on leaving a neat sample of the beach deposit in a vial for two days two apparent layers formed (Figure 12), an upper slightly cloudy liquid layer and a white 'solid' lower layer. The upper layer gave $\mathrm{pH} 4-5$ when tested using $\mathrm{pH}$ paper. An FTIR spectrum of the upper phase is presented in Figure 13. 


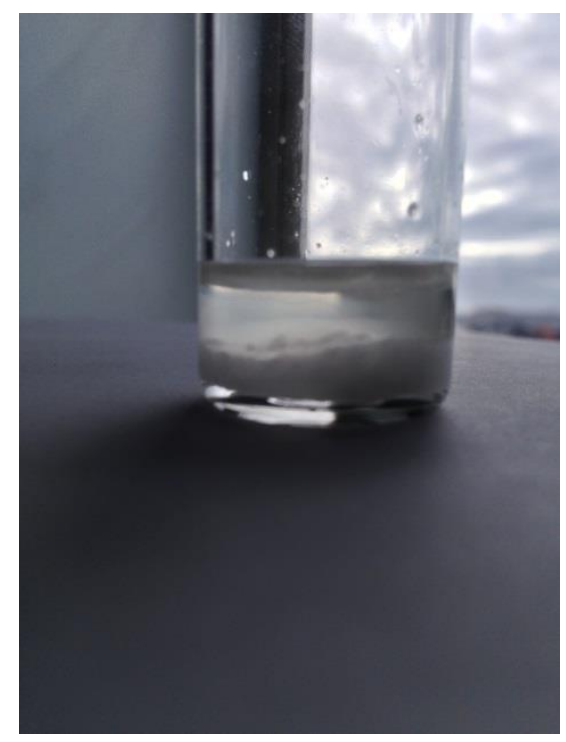

Figure 12. Photograph of neat sample left to stand for two days.

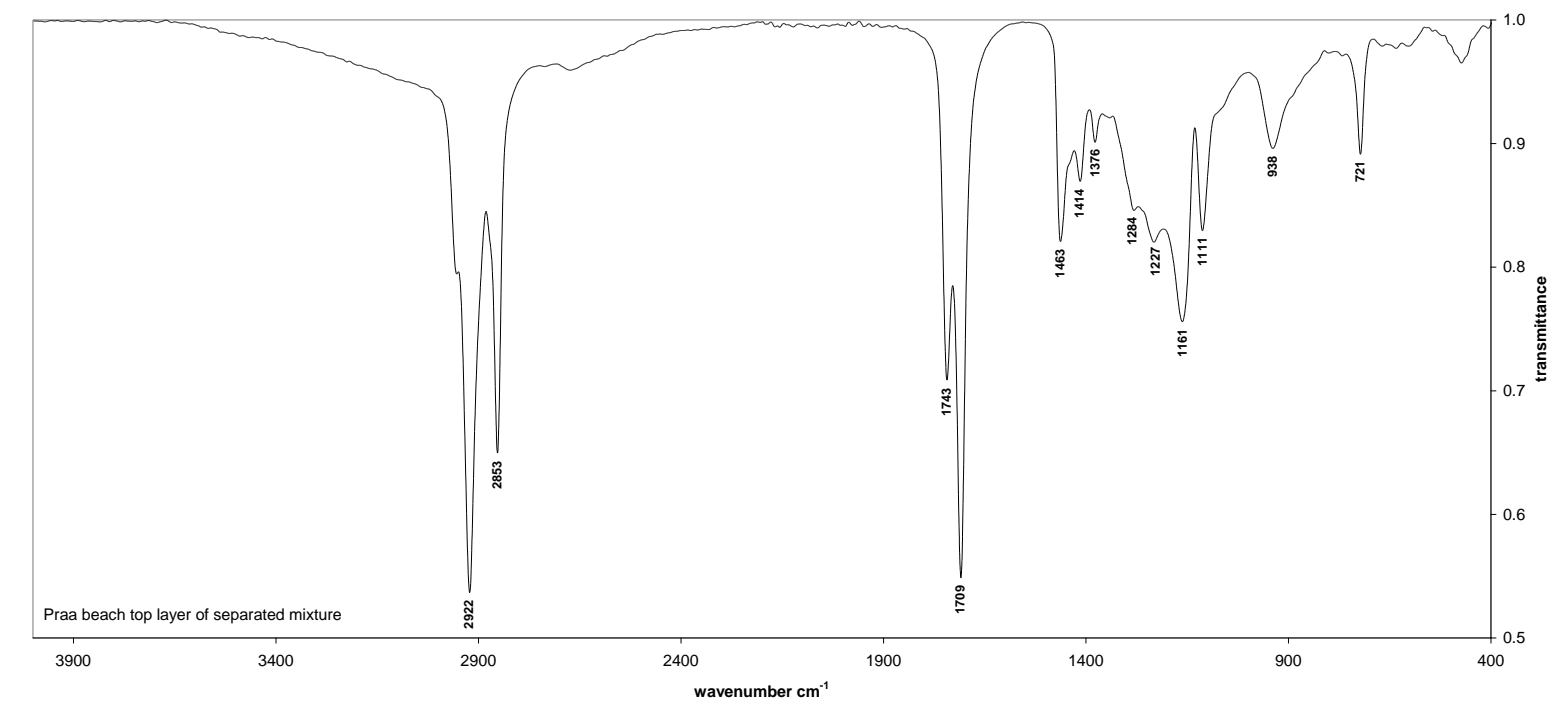

Figure 13. IR spectrum of upper phase separated after standing sample for two days.

It was concluded that the Praa beach deposit was not coconut oil or fresh palm oil but was possibly a partially degraded commercial cooking oil (Figure 14). In essence, at the time of collection and analysis it was a mixture of fatty acids, mono-, di- and tri glycerides. 


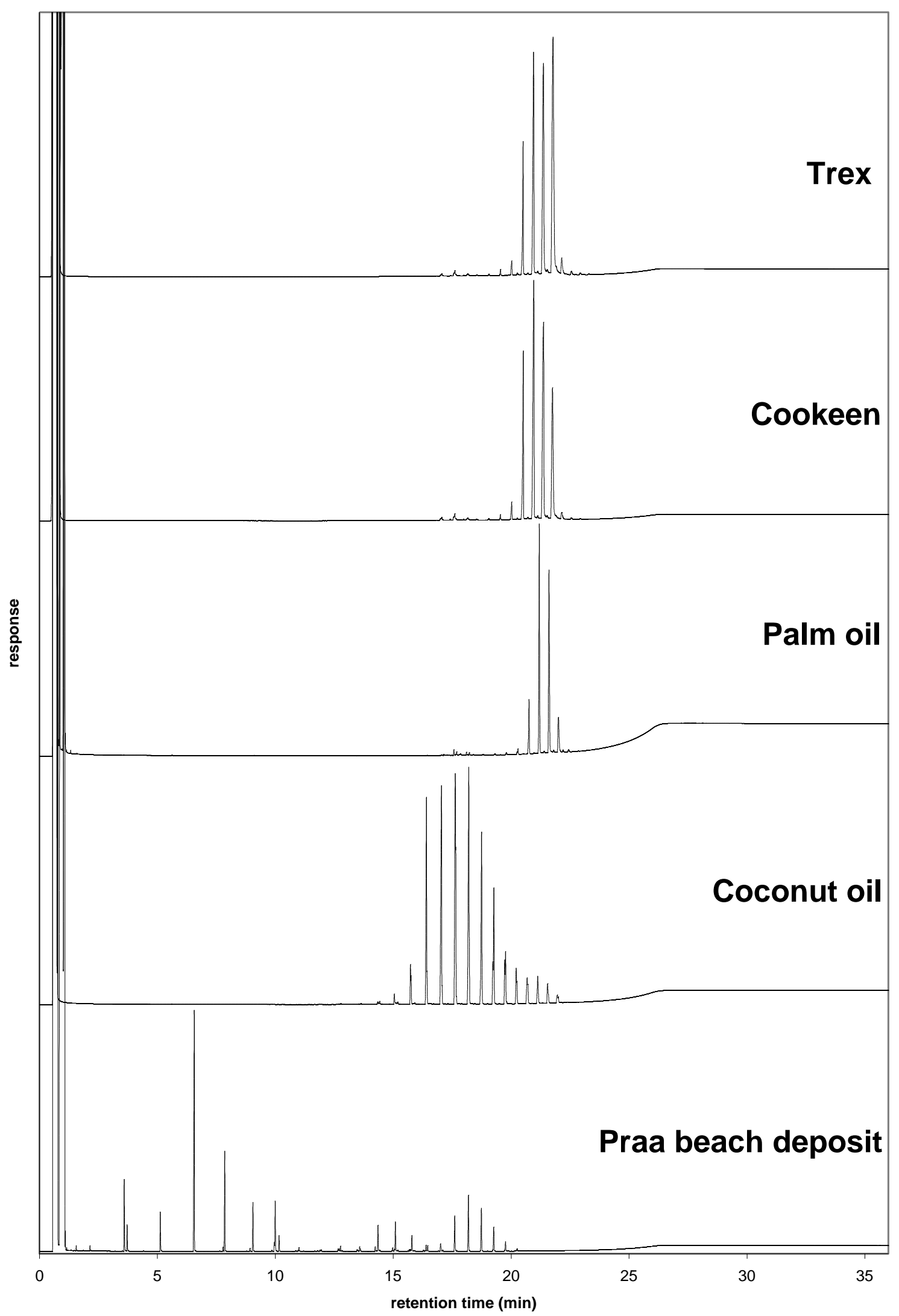

Figure 14. HTGC chromatograms of Praa beach deposit and commercial cooking oils 


\section{Analysis of beach deposits from Chesil and Kimmeridge, Dorset collected on $20^{\text {th }}$ February 2014.}

Three beach deposit samples in plastic bags were supplied on 20.02.14. Laboratory codes were assigned to each sample and each sample was described and photographed (Table 15). Sub-samples of 'virgin' material from samples CF14A and KF14 were taken by breaking a piece of the material and carefully scraping a sample of the exposed face with a spatula (Table 15). A sub-sample of CF14B was obtained by dipping the end of a glass pipette into the material.

Samples were diluted to $10 \mathrm{mg} / \mathrm{mL}$ in solvent. For samples CF14A and KF14 some material was visibly not dissolved after vortex mixing (10s) and samples were heated $\left(70^{\circ} \mathrm{C} / 5 \mathrm{~min}\right)$ to aid dissolution. Sample CF14B was readily soluble at the required concentration following vortex mixing (10 s). All samples were analysed using FTIR spectroscopy (Figure 16) and further diluted to $1 \mathrm{mg} / \mathrm{mL}$ (CF14A and KF14) or diluted and derivatised with BSTFA/TMCS (CF14B) for HTGC (Figure 17) and GC-MS analysis (Figure 18 -23). 
Table 15. Beach deposit samples from Chesil and Kimmeridge, U.K.

\begin{tabular}{|l|c|c|c|}
\hline \multicolumn{1}{|c|}{ Location } & Kimmeridge Feb 14 & Chesil Feb 14 & Chesil Feb 14 \\
\hline $\begin{array}{l}\text { Laboratory } \\
\text { code }\end{array}$ & KF14 & CF14A & CF14B \\
\hline $\begin{array}{l}\text { Descriptio } \\
\mathbf{n}\end{array}$ & Hard, white, brittle & Soft, white & Soft, orange-yellow \\
\hline Odour & No obvious odour & Musty odour & Foul smelling \\
\hline $\begin{array}{l}\text { Sample } \\
\text { mass (mg) }\end{array}$ & 12.1 & 62.0 & DCM \\
\hline Solvent & cyclohexane & cyclohexane & Soluble (vortex) \\
\hline Solubility & Soluble (heating) & Soluble (heating) & \\
\hline & kimnerincE FFB 14 & & \\
\hline
\end{tabular}

CF14A and KF14: FTIR (Figure 16a and b) demonstrated that samples CF14A and KF14 were hydrocarbons $\left(-\mathrm{CH}_{2}\right.$ and $-\mathrm{CH}_{3}$ asym/sym str. at 2850 and $2922 \mathrm{~cm}^{-1}$ and $-\mathrm{CH}_{2}$ and $-\mathrm{CH}_{3}$ asym/sym bend. at $1450 \mathrm{~cm}^{-1}$ ), most probably waxes. Their molecular weight distribution was determined using HTGC (Figure 17b and c). Both samples comprised similar n-alkane distributions from $n \mathrm{C}_{20}$ to around $n \mathrm{C}_{48}$ with maximum at $n \mathrm{C}_{27}$, although $\mathrm{KF} 14$ had slightly increased abundance of $n$-alkanes $>n \mathrm{C}_{30}$ and a more pronounced odd/even distribution around $n \mathrm{C}_{27}$. Peak elution patterns between $n$-alkanes were almost identical.

CF14B: IR analysis of CF14B (Figure 16c) indicated a band representative of carboxylic acid or ketone group $\left(1708 \mathrm{~cm}^{-1}\right)$ the broad baseline band between $2700-3300 \mathrm{~cm}^{-1}$ suggested that this was a carboxylic acid, characteristic hydrocarbon transmittances (as above: 2851, 2919 and $1463 \mathrm{~cm}^{-1}$ ) were also present. HTGC analysis (Figure 17d) showed that this sample was dominated by two (possibly three) components, revealed as peaks eluting between $10-$ 12 minutes. From GC-MS analysis (Figures 18-23), major peaks were tentatively identified as 
$\mathrm{C}_{16: 0}, \mathrm{C}_{18: 2}, \mathrm{C}_{18: 1}$ and $\mathrm{C}_{18: 0}$ acid trimethylsilyl esters and glycerol tris TMS ester (early eluting 10.71 minutes).

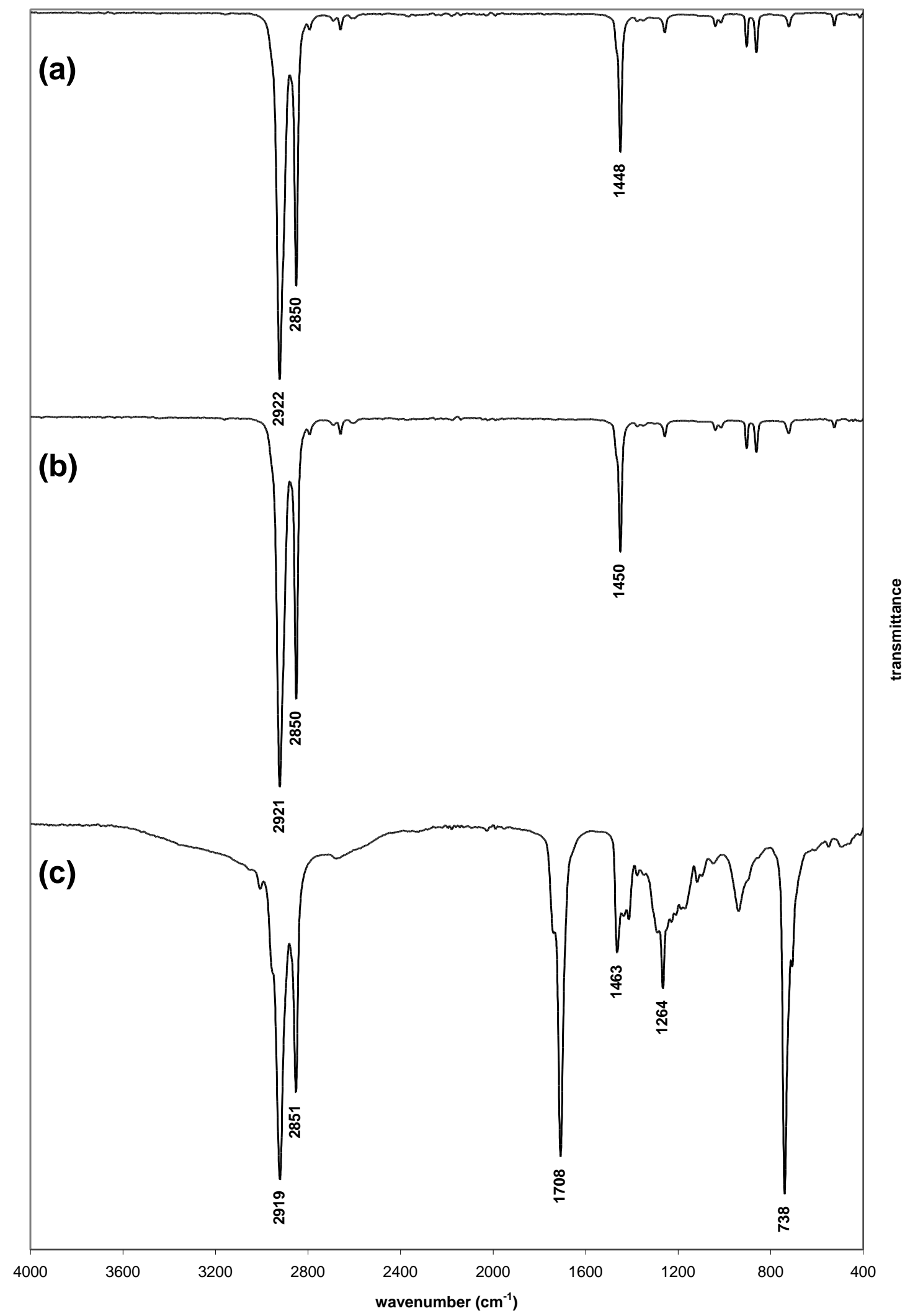

Figure 16. IR spectra of beach deposits (a) CF14A (b) KF14 (c) CF14B 


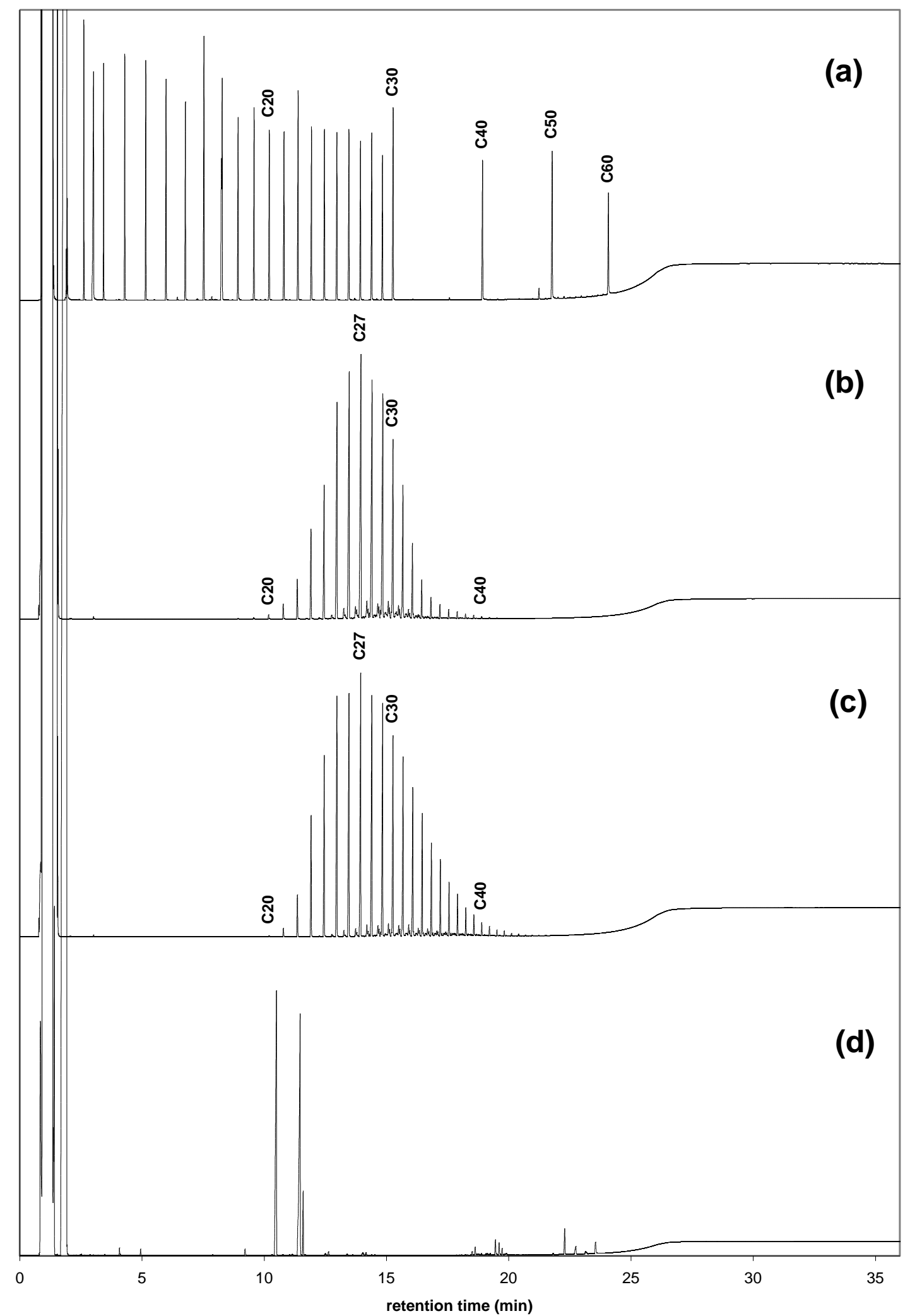

Figure 17. HTGC chromatograms of (a) $n$-alkane standard (b) and (c) hot injected samples CF14A and KF14, respectively, and (d) CF14B TMS. 


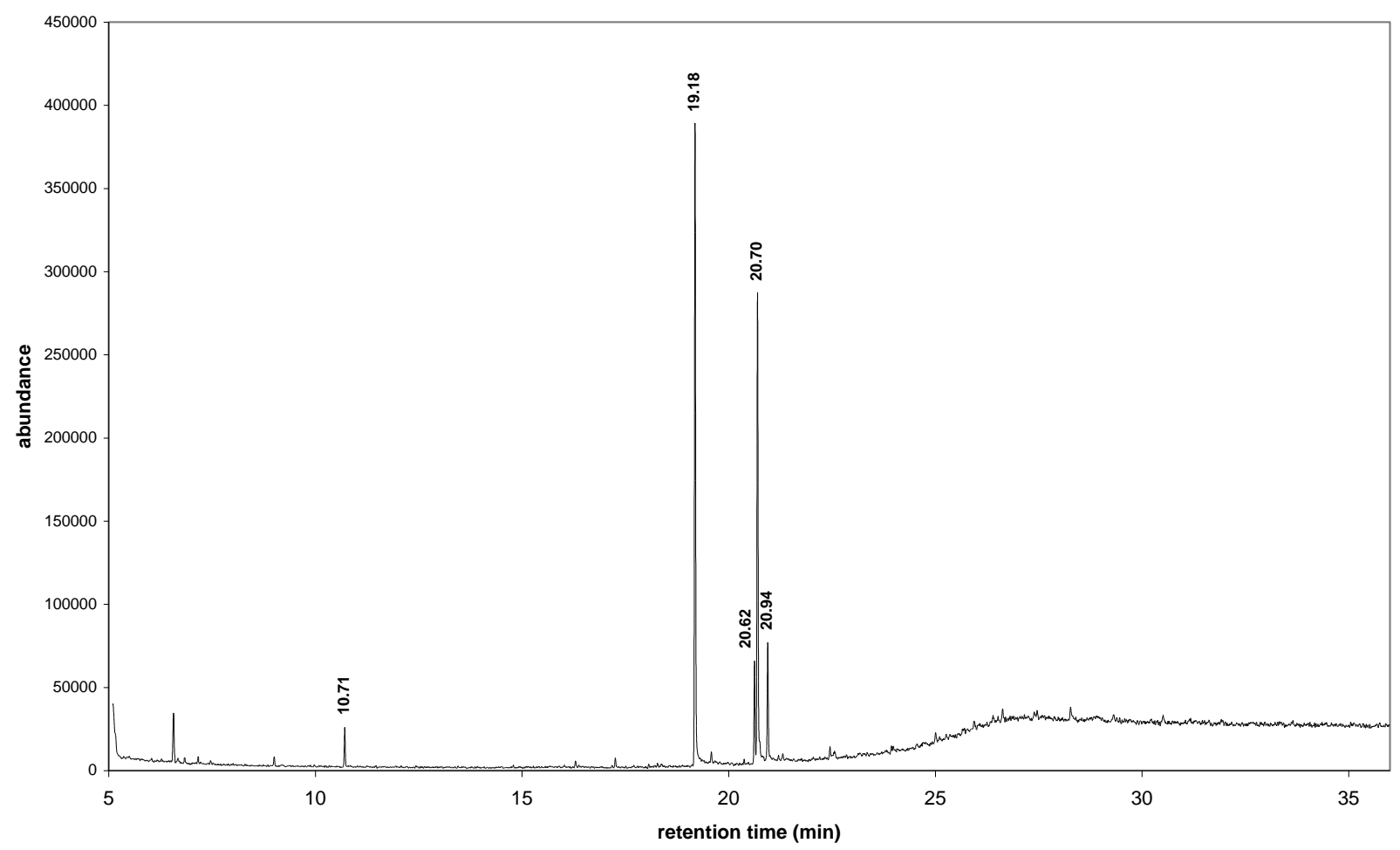

Figure 18. GCMS total ion chromatogram of sample CF14B.

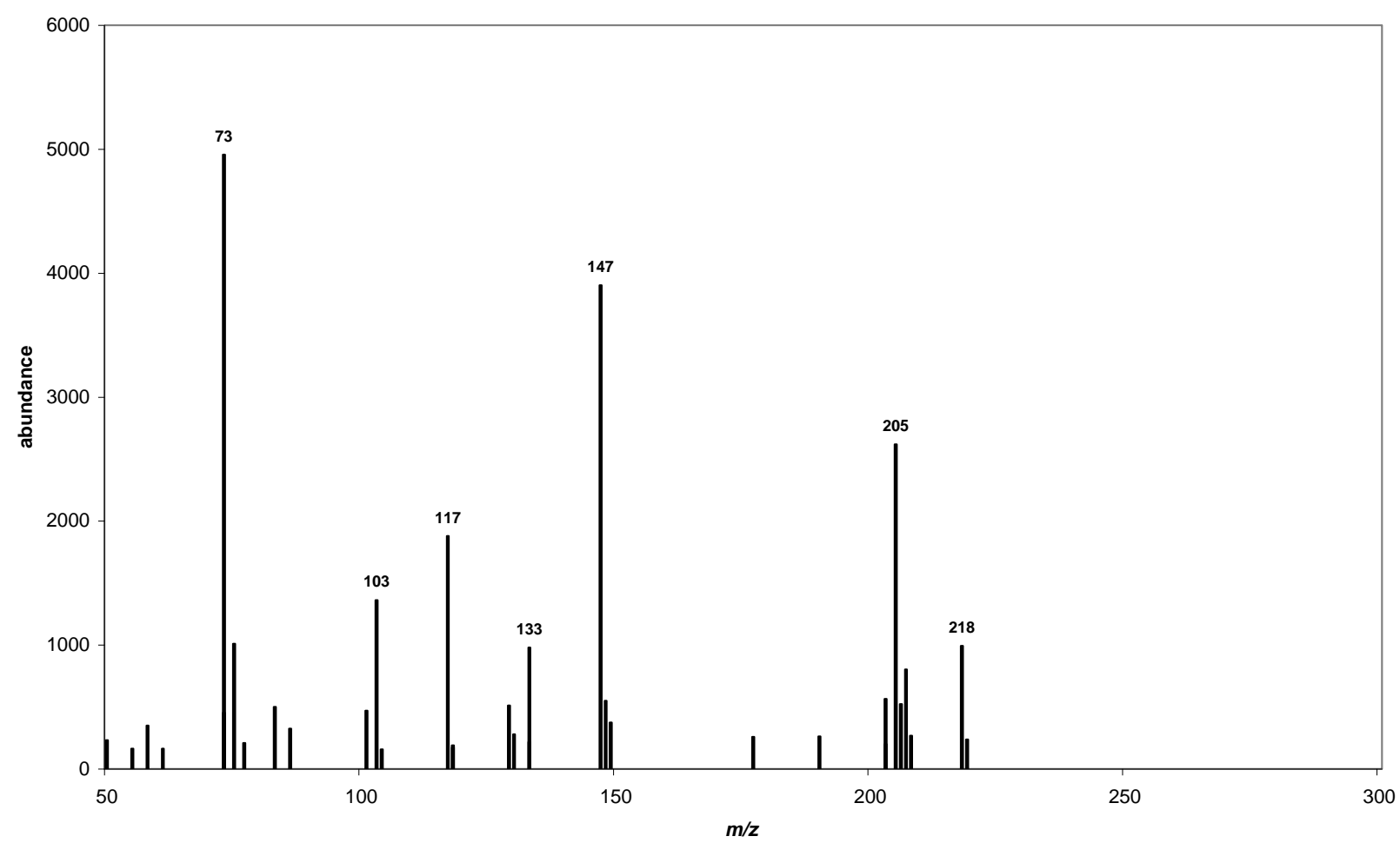

Figure 19. Mass spectrum of peak at 10.71 minutes (Figure 18); best NIST library match was with TrisTMS ester of glycerol. 


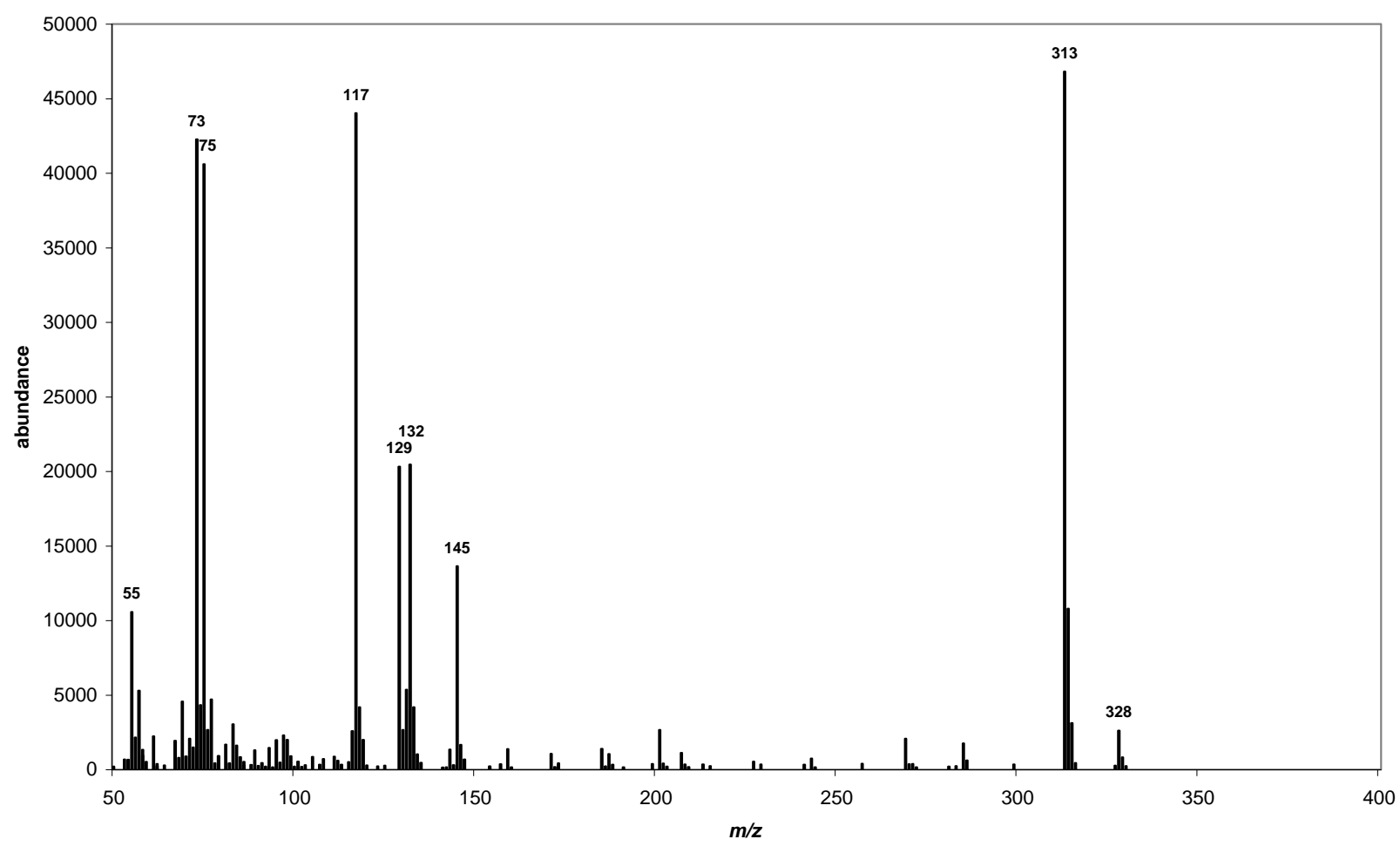

Figure 20. Mass spectrum of peak at 19.18 minutes (Figure 3); best NIST library match was with hexadecanoic acid TMS ester).

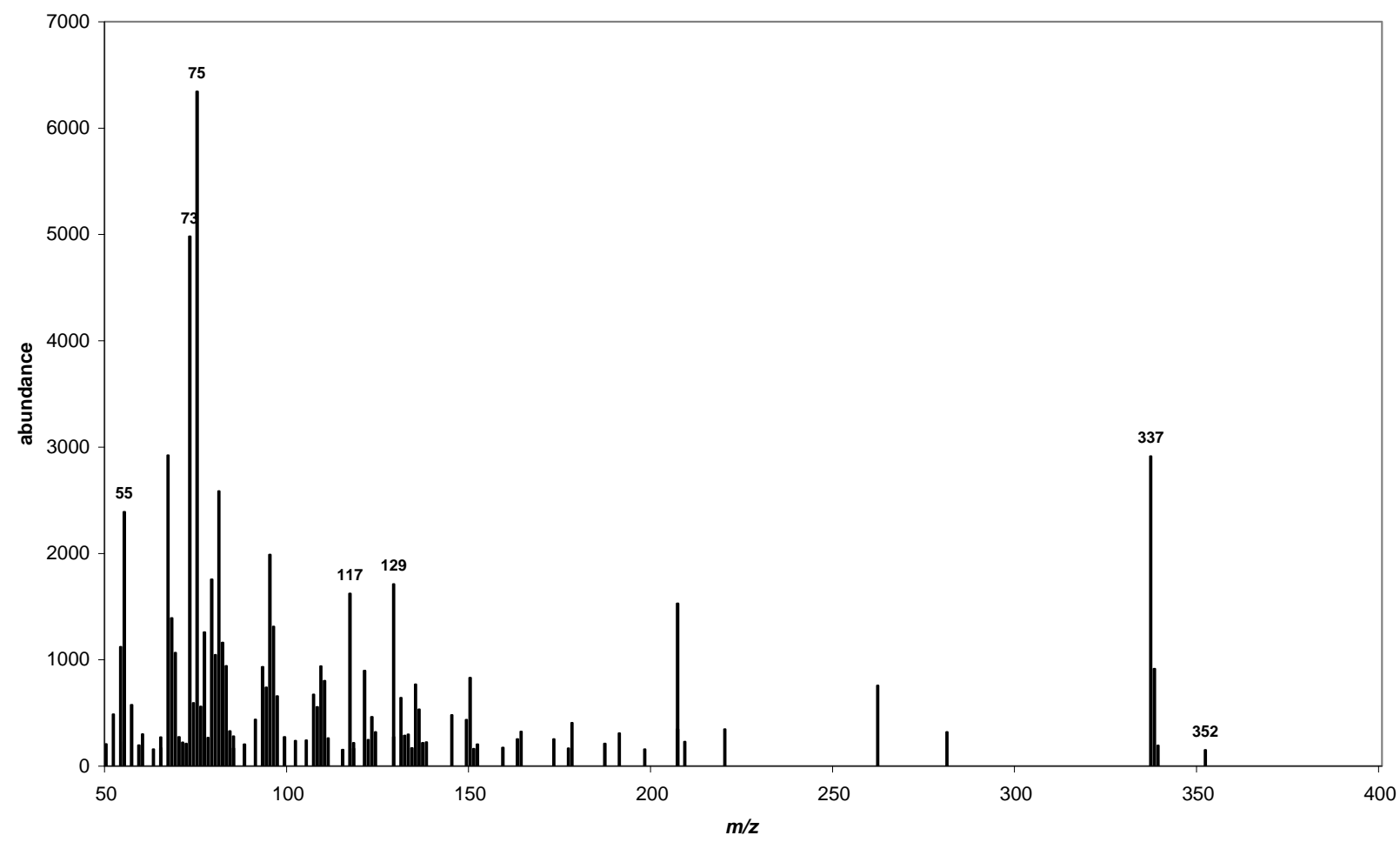

Figure 21. Mass spectrum of peak at 20.62 minutes (Figure 3); best NIST library match was with octadecadienoic acid TMS ester). 


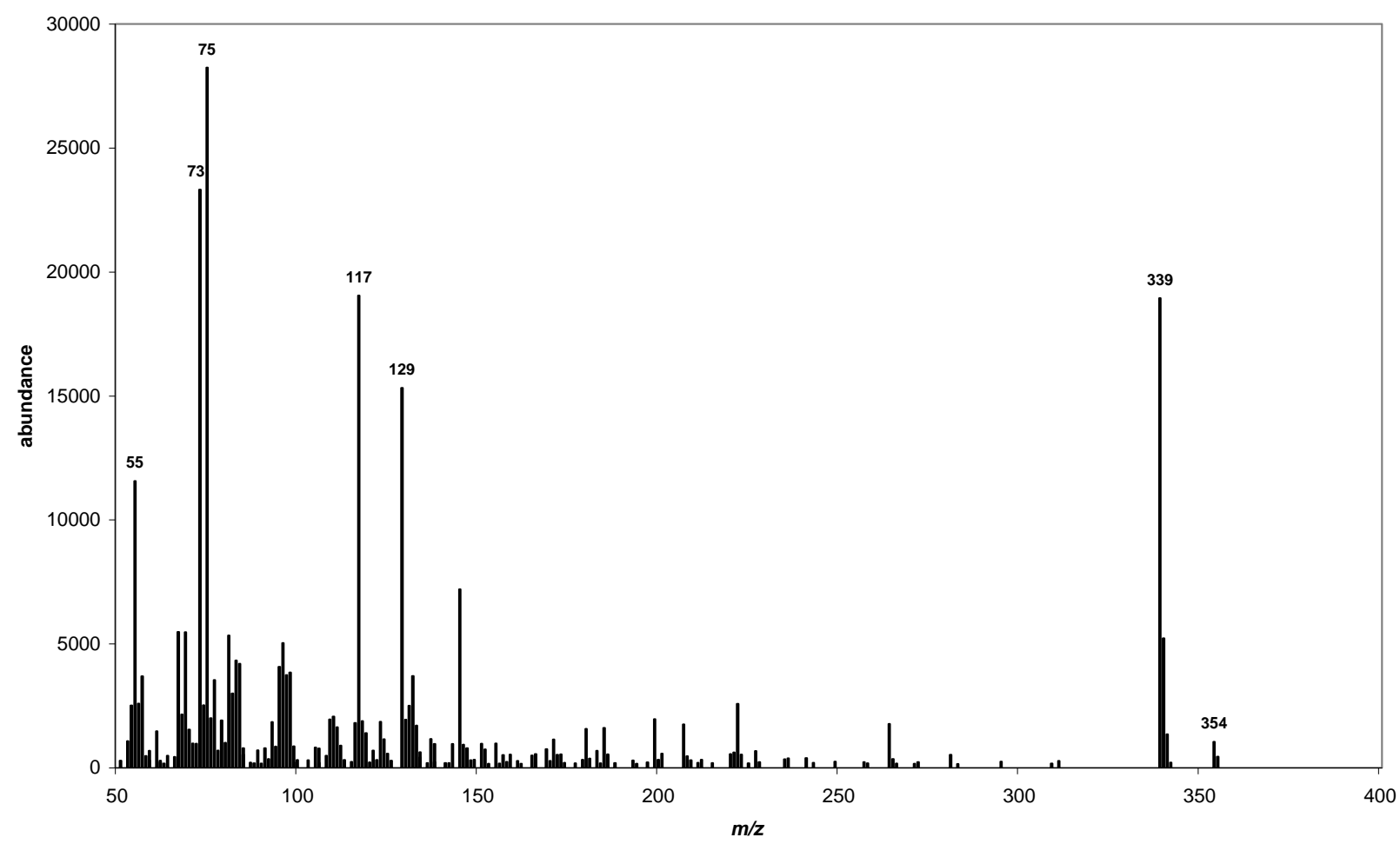

Figure 22. Mass spectrum of peak at 20.70 minutes (Figure 3); best NIST library match was with octadecenoic acid TMS ester).

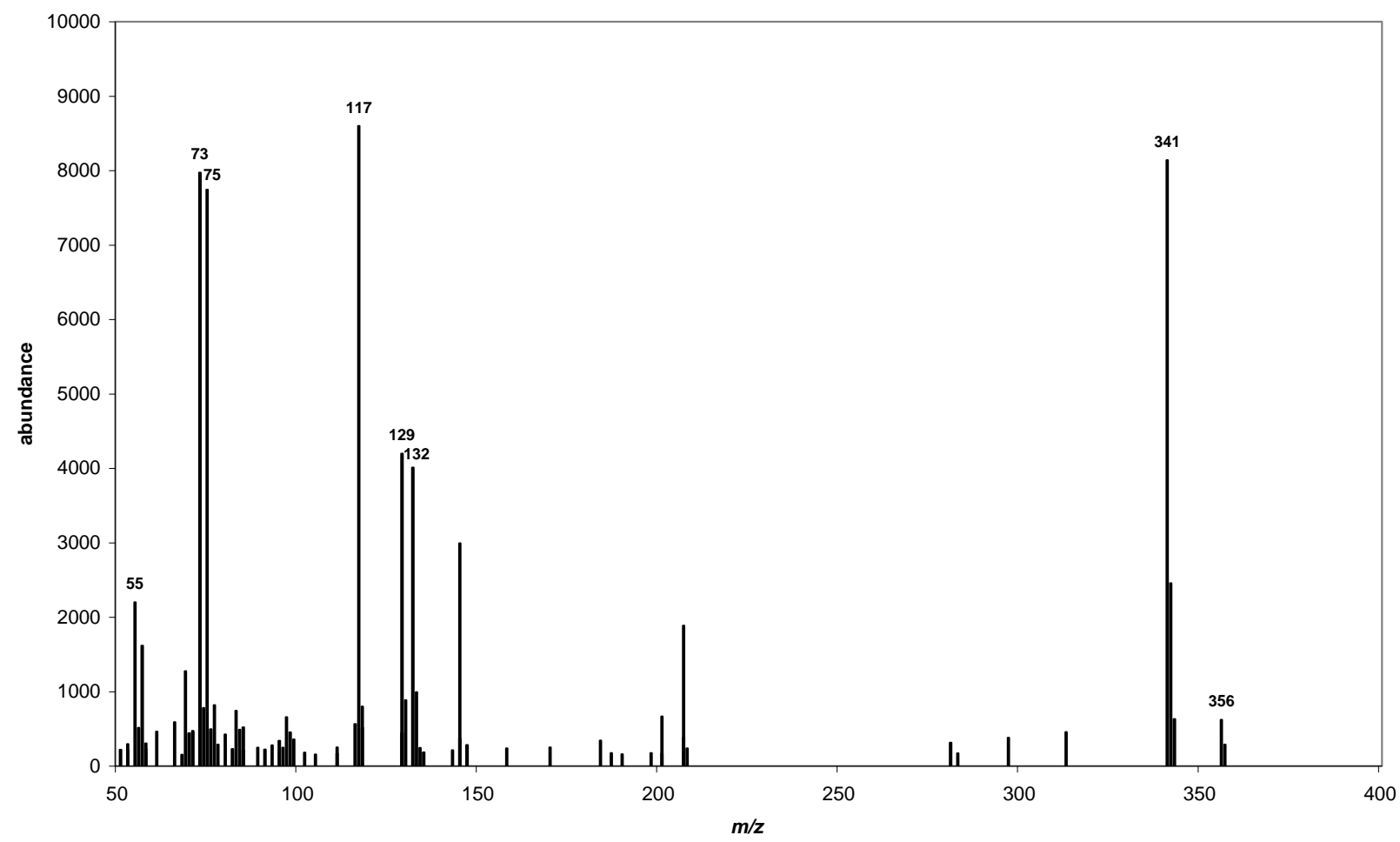

Figure 23. Mass spectrum of peak at 20.94 minutes (Figure 3); NIST library match octadecanoic acid TMS ester). 
The early eluting but major peaks from the HTGC appeared to be due to hexadecanoic and octadecanoic acids and monoene and diene forms of the octadecanoic acid. This seems to match reasonably well with data reported in the literature for red palm oil (red palm oil: palmitic $(42 \%)$, oleic $(45 \%)$, linoleic $(10 \%)$ and linolenic $(0.3 \%))$.

From these results from analysis of the Chesil and Kimmeridge beach deposits by FTIR and HTGC it was concluded that two were simple wax 'balls', whilst the orange/yellow odorous sample was possibly a substantially degraded red palm oil or similar. Degradation of this latter material had apparently progressed further than that of the corresponding suspected degraded oil sample collected from Praa beach (cf acid and mono-, di- and triglyceride distributions shown in Figure 14 with Figure 17d).

5. Analysis of beach deposit collected from Penzance beach, Cornwall, U.K. on $2^{\text {rd }}$ February 2014

A beach deposit (Figure 24) from Penzance beach, collected on $23^{\text {rd }}$ February by Dr Weibke Schmidt, then University of Plymouth, was sampled by breaking and scraping the exposed surface. The sample was diluted in cyclohexane to $10 \mathrm{mg} / \mathrm{mL}$ for FTIR (Figure 25) and further diluted (x10) for HTGC analysis (Figure 26).

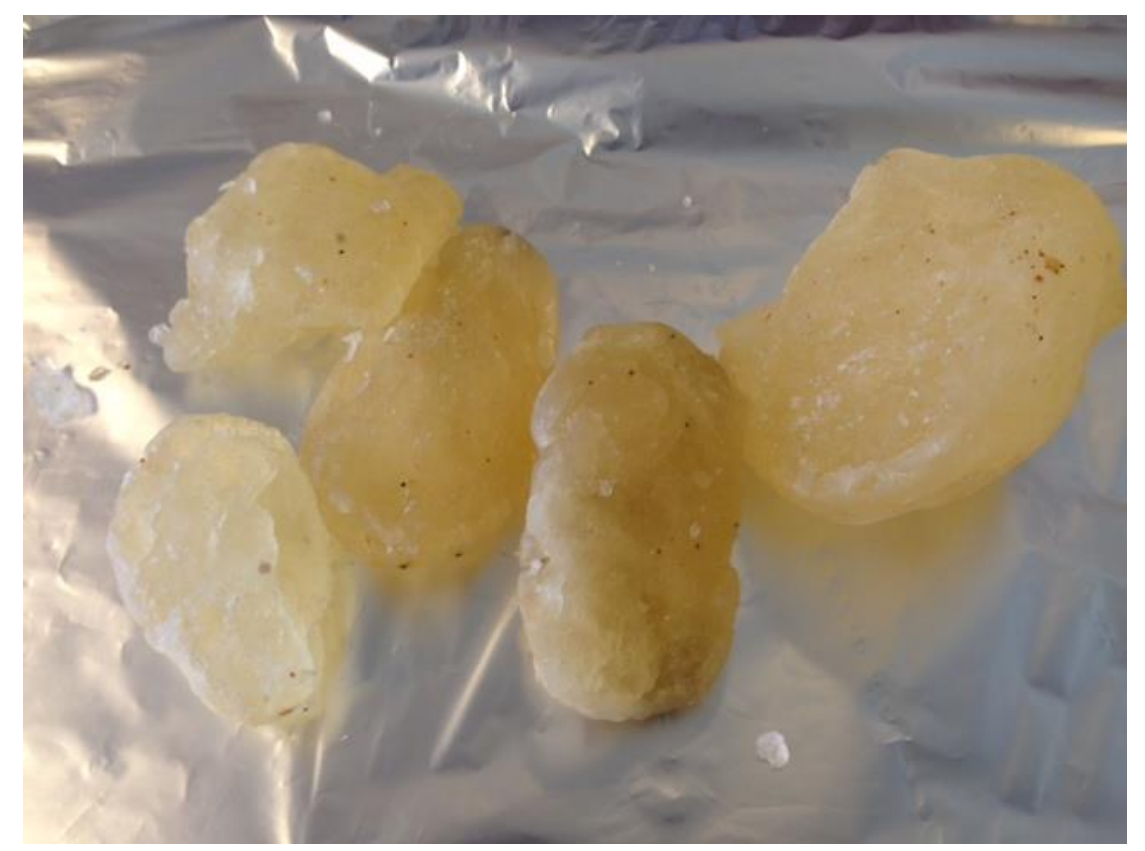

Figure 24. Beach deposits collected from Penzance by Dr W Schmidt.

FTIR (Figure 25) demonstrated that the sample comprised hydrocarbons $\left(-\mathrm{CH}_{2}\right.$ and $-\mathrm{CH}_{3}$ asym/sym str. at 2850 and $2922 \mathrm{~cm}^{-1}$ and $-\mathrm{CH}_{2}$ and $-\mathrm{CH}_{3}$ asym/sym bend. at $1450 \mathrm{~cm}^{-1}$ ), most probably waxes and the molecular weight distribution was determined using HTGC 
(Figure 26). The sample comprised $n$-alkane distribution from $n \mathrm{C}_{16}$ to around $n \mathrm{C}_{36}$ with maximum at $n \mathrm{C}_{21}$.

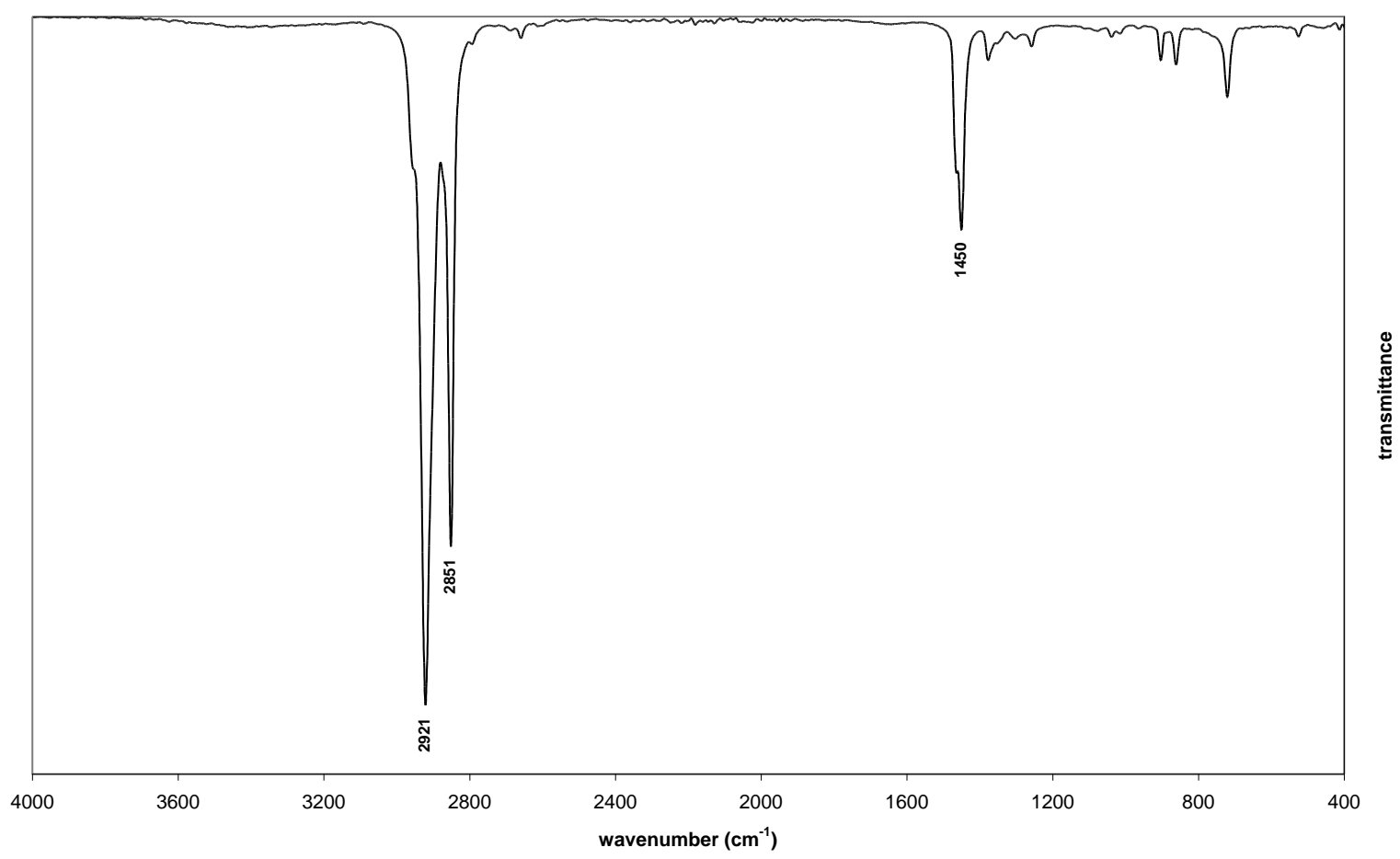

Figure 25. FTIR spectrum of beach deposit from Penzance beach, Cornwall, U.K.

It was concluded that the sample consisted of a paraffin wax. 


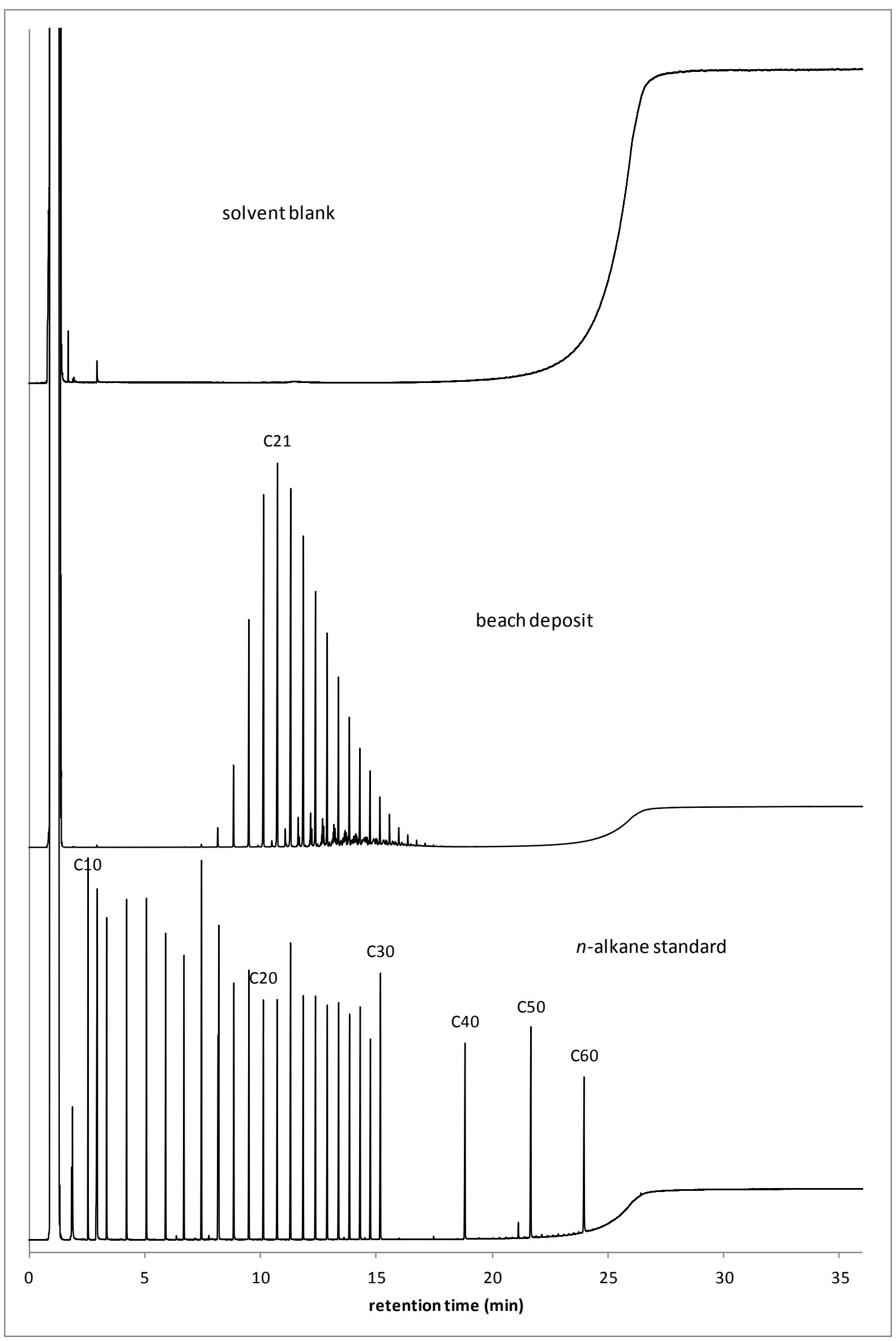


Figure 26. HTGC chromatograms of solvent blank, beach deposit sample and $n \mathrm{C}_{10-60}$ alkanes.

\section{Analysis of suspected ambergris samples from New Zealand and Thailand analysed on 19th December 2016}

Two samples, thought to be ambergris by the finders, were received in our laboratory on 14.12.16 (supplied by Dr V. Thoss, Bangor University): a pale brown sand-like material that flowed freely (Figure 27a; marked as REI Masters NZ - assigned laboratory code 'RM-AMB' was found at Kaipara harbour, New Zealand by R. Masters and described by the finders as weighing about $350 \mathrm{~g}$ and about palm sized; a second, hard yellow substance (Figure 27b; marked C. Harrison - assigned laboratory code ' $\mathrm{CH}-\mathrm{AMB}$ ') and another sample of hard yellow material (Figure 27c; presumably a second sample of $\mathrm{CH}-\mathrm{AMB}$ supplied in a box marked Charlie Boots - assigned laboratory code 'CB-AMB'), were found in Koh Samui in Thailand by C. Harrison.

Samples were weighed into $7 \mathrm{~mL}$ vials (Table 29) and extracted with dichloromethane (DCM; $3 \times 2 \mathrm{~mL}$ ) with sonication ( $5 \mathrm{~min}$ ). It should be noted that the RM-AMB sample formed a sticky gelatinous layer over the DCM (Figure 28) whilst CH-AMB and CB-AMB appeared to be virtually insoluble in DCM (Figure 28). Samples were then centrifuged ( $2500 \mathrm{rpm} / 5 \mathrm{~min}$ ) and the supernatant or liquid phase decanted to a pre-weighed vial through a pre-extracted (DCM, 25h Soxhlet) cotton wool plug in a Pasteur pipette. Solvent was removed from the extract under a gentle stream of nitrogen $\left(50^{\circ} \mathrm{C}\right)$ and the extract weighed and reconstituted with $\mathrm{DCM}$ to $10 \mathrm{mg} / \mathrm{mL}$ for analysis using FTIR spectroscopy (Figure 30 ).
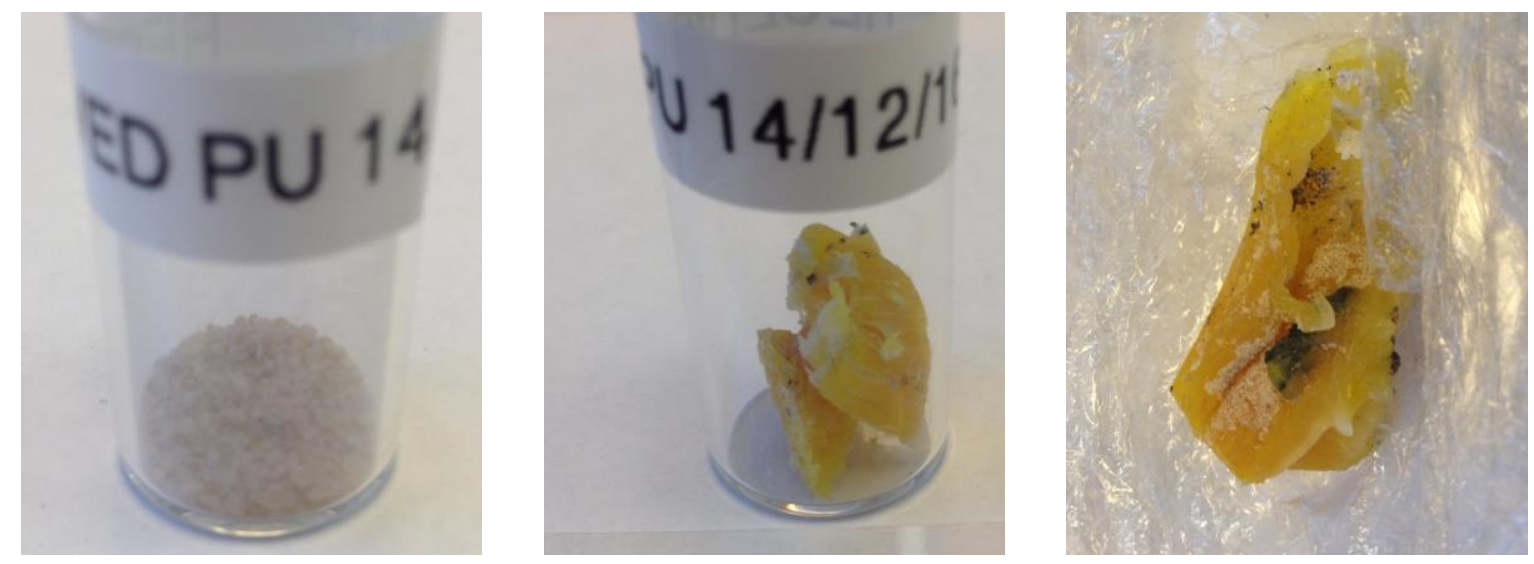

Figure 27. Samples prior to extraction. RM-AMB sand-like material (a,left), $\mathrm{CH}-\mathrm{AMB}$ hard yellow material (b, centre) and CB-AMB hard yellow material (c, right). 


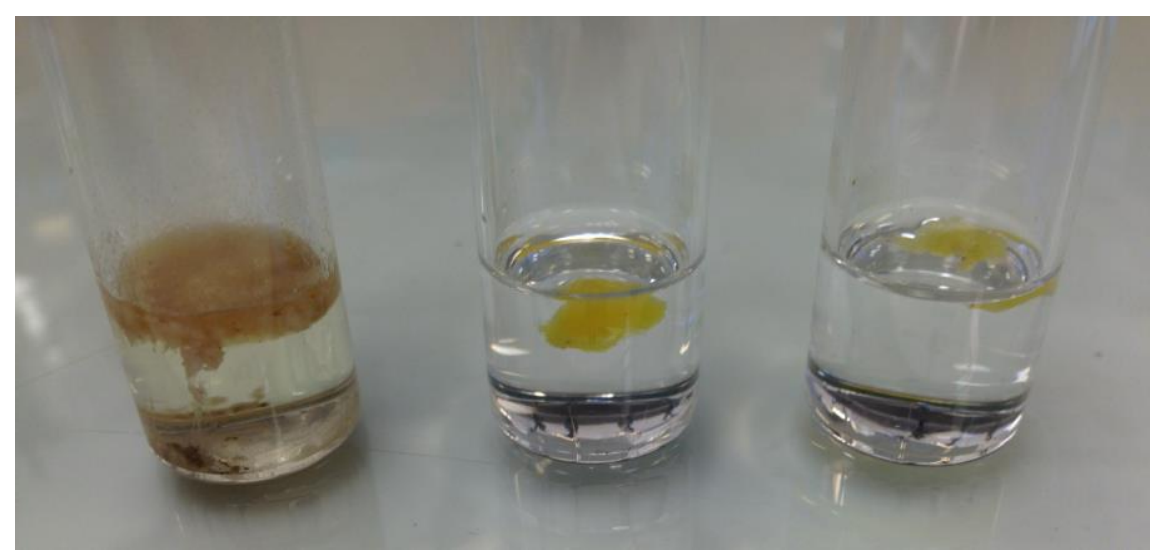

Figure 28. Extraction of RM-AMB resulted in sticky gelatinous layer over DCM (left) and $\mathrm{CH}$ $A M B$ and $C B-A M B$ were apparently poorly soluble in DCM (centre and right).

Table 29. Gravimetric data from extraction of suspected ambergris samples

\begin{tabular}{|l|c|c|c|}
\hline & RM-AMB & CH-AMB & CB-AMB \\
\hline Sample $(\mathrm{mg})$ & 158.3 & 45.5 & 45.0 \\
\hline Extract $(\mathrm{mg})$ & 65.1 & $<0.1$ & $<0.1$ \\
\hline Recovery \% & 41 & $<0.2$ & $<0.2$ \\
\hline
\end{tabular}

Samples $\mathrm{CH}-\mathrm{AMB}$ and $\mathrm{CB}-\mathrm{AMB}$ were poorly soluble in $\mathrm{DCM}(<0.2 \%$ recovery) suggesting that they were not ambergris. This was supported by the FTIR spectra where the samples lacked many of the 'signals' observed in authentic ambergris such as the broad $\mathrm{OH}$ peak centred around $3400 \mathrm{~cm}^{-1}$, the small peak at $3064 \mathrm{~cm}^{-1}$ and the peak at $1644 \mathrm{~cm}^{-1}$ (Figure 30). In contrast, the FTIR spectrum of the RM-AMB sample had some features resembling those observed in authentic ambergris (Figure 30), e.g. small peak at $3077 \mathrm{~cm}^{-1}$, broad $\mathrm{OH}$ band centred around $3386 \mathrm{~cm}^{-1}$ and the small peak around $1640 \mathrm{~cm}^{-1}$. There were however some differences too, the broad $\mathrm{OH}$ band stretched to around $2700 \mathrm{~cm}^{-1}$ and strong peak at 1692 $\mathrm{cm}^{-1}$ indicating the presence of a carboxylic acid group. We chose to undertake further analysis of this sample using GCMS.

A nominal $20 \mu \mathrm{L}$ of RM-AMB extract was transferred to a $\mathrm{GC}$ vial, dried and derivatised with SYLON BTZ (BSA/TMCS/TMSI, 3:2:3; nominal $40 \mu \mathrm{L} ; 70^{\circ} \mathrm{C} ; 2 \mathrm{~h}$ ) prior to dilution in $1 \mathrm{~mL}$ cyclohexane and analysis using an Agilent GC-MSD (7890A gas chromatograph with 7683B series autosampler and 5975A mass selective detector; $\mathrm{m} / z 50-550$ at $70 \mathrm{eV}$ ). A $1 \mu \mathrm{L}$ aliquot was injected (autosampler; splitless at $250^{\circ} \mathrm{C}$ ) on to a DB5-MS column ( $30 \mathrm{~m} \times 0.25 \mathrm{~mm} \times$ $0.25 \mu \mathrm{m}$ ) with helium carrier gas (constant flow mode $1 \mathrm{~mL} \mathrm{~min}^{-1}$ ), the oven temperature programmed from $40-210^{\circ} \mathrm{C}$ at $10^{\circ} \mathrm{C} \mathrm{min}{ }^{-1}$ and from $210-300^{\circ} \mathrm{C}$ at $5^{\circ} \mathrm{C} \mathrm{min}^{-1}$ with 10 minute hold, transfer line at $280^{\circ} \mathrm{C}$ and source at $230^{\circ} \mathrm{C}$. 
The total ion chromatogram of the trimethylsilylated extract of sample RM-AMB is presented in Figure 31 along with that of an authenticated sample of ambergris (Rowland and Sutton, 2017), derivatised in the same manner. It is readily apparent that the peaks in the RM-AMB sample do not align with those of the authentic ambergris sample. The mass spectra of the RM-AMB peaks also did not match those of ambrein, coprostanol, epicoprostanol or their derivatives.

It was concluded that none of the samples were ambergris. The exact identity of the samples was not determined. 


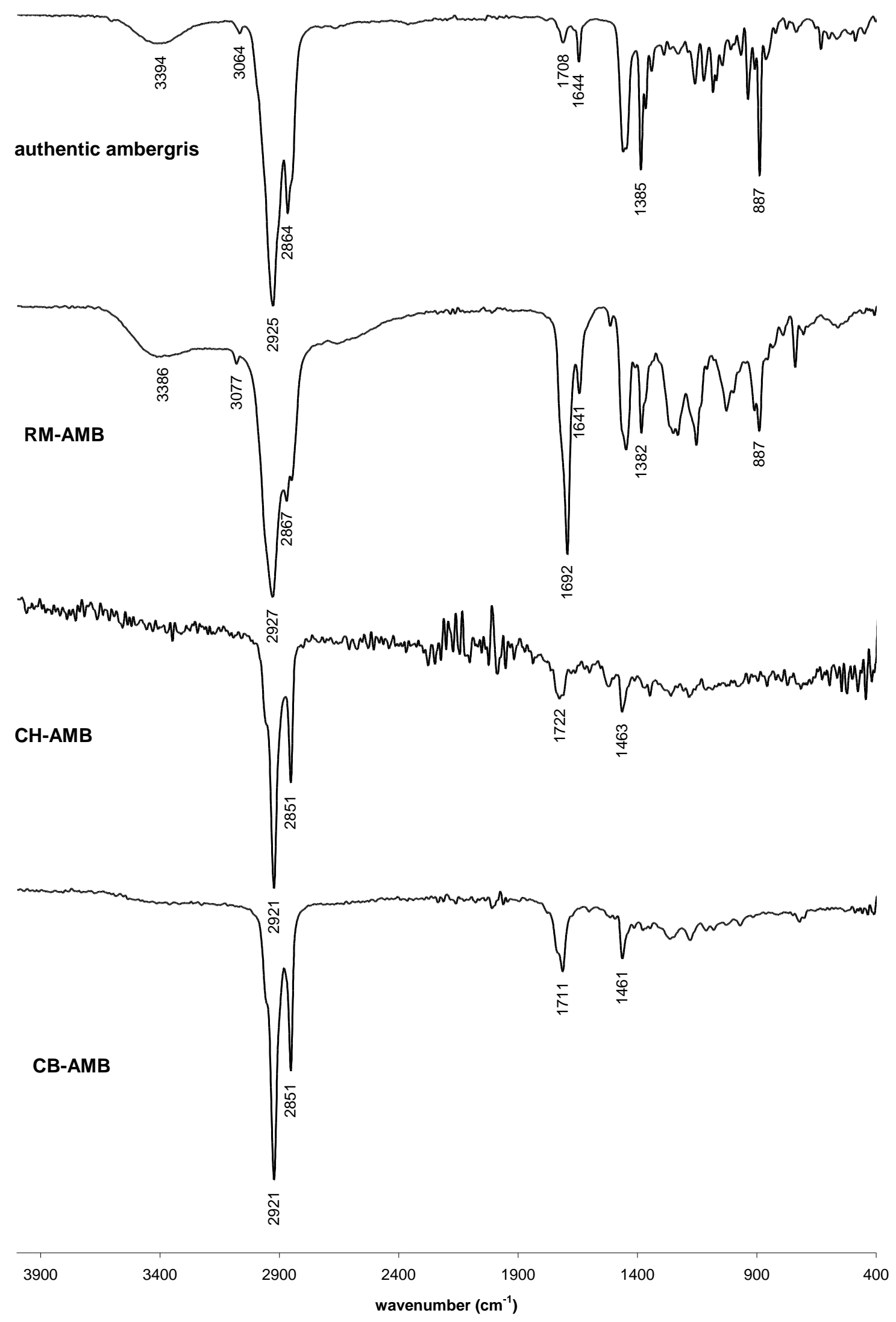

Figure 30. FTIR spectra of authentic ambergris (top) and extracts obtained from RM-AMB, $\mathrm{CH}-\mathrm{AMB}$ and $\mathrm{CB}-\mathrm{AMB}$. 


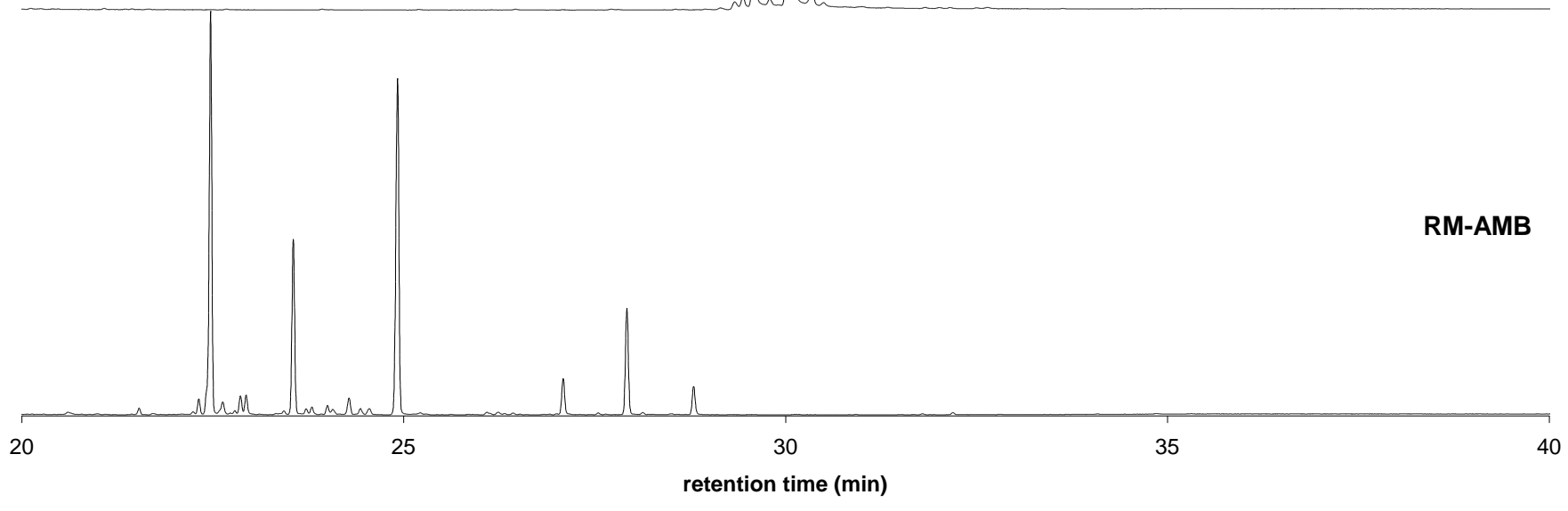

Figure 31. GCMS total ion chromatograms of trimethylsilylated (SYLON BTZ) authentic ambergris (upper) and RM-AMB sample (lower).

\section{Analysis of suspected ambergris samples collected from a beach at Walpole, Western Australia in about 2012.}

Three samples (Walpole 1-3) of suspected ambergris (suspected by finder) collected in about 2012 from a beach near Walpole, WA, were supplied by Dr A. G. Scarlett, Curtin University (supplied to AGS by the finder). Aliquots of samples diluted in DCM were examined by GCMS both before and after derivatisation (Sylon BTZ; TMS derivatives). A sample of authenticated non-derivatised and derivatised ambergris (Rowland and Sutton 2017, sample 11 'silver' reference) was also examined under the same conditions (Figure 32). Major constituents of the Walpole samples produced mass spectra consistent with those of higher plant triterpenoids.

It was concluded that the Walpole samples were probably higher plant resins. 


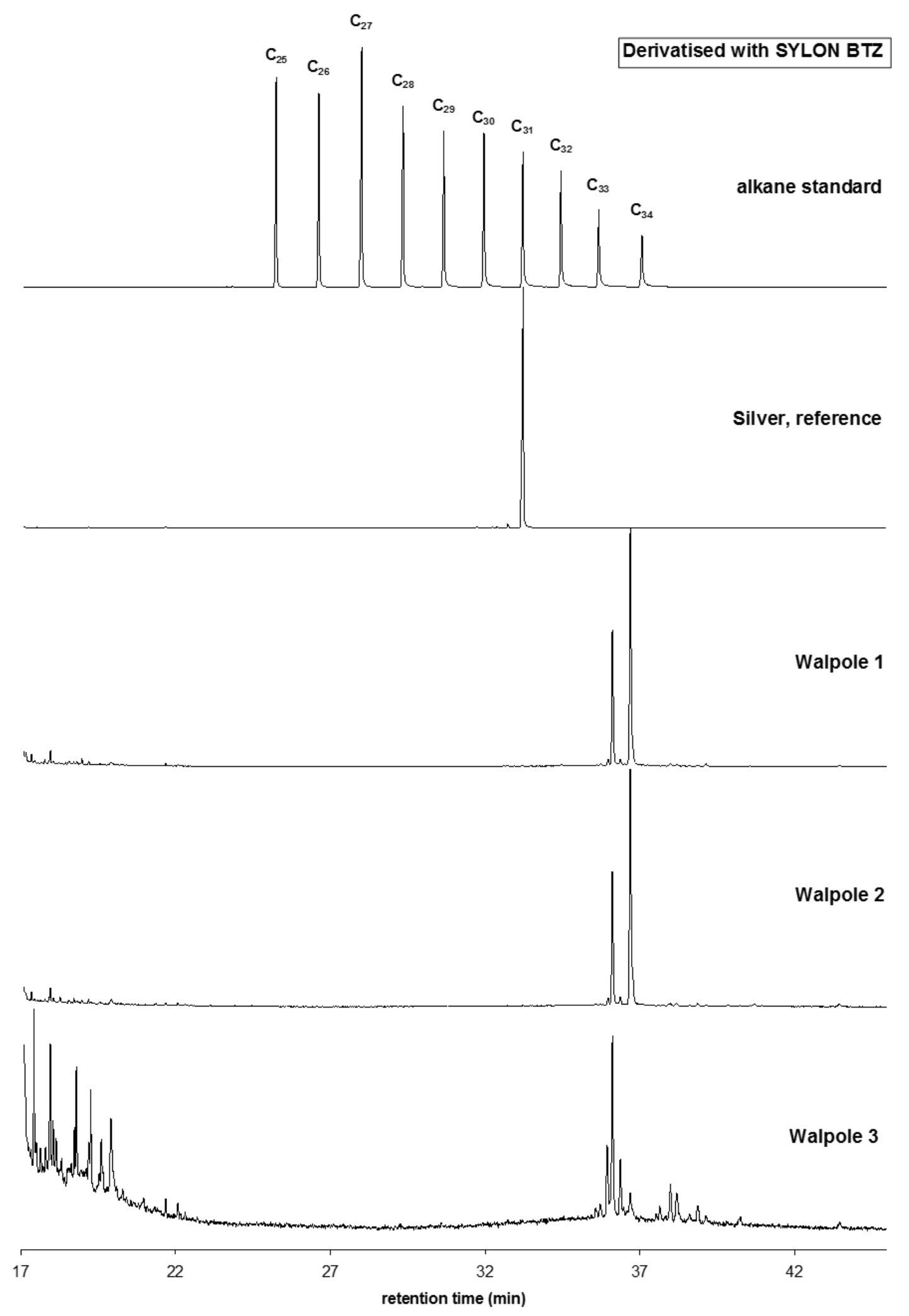

Figure 32. Total ion chromatograms of $n$-alkane standard, and trimethylsilylated Silver reference (authenticated jetsam ambergris; Sample 11 of Rowland and Sutton, 2017) and Walpole beach samples. 


\section{Analysis of putative ambergris sample bequeathed to Natural History Museum, London by Prof A. Liversidge FRS.}

A sample labelled as 'ambergris', was supplied by the Natural History Museum London, U.K. This sample was originally bequeathed by the estate of Professor Archibald Liversidge FRS and weighed 176g. Liversidge lived 17 November 1847 - 26 September 1927 and was an English-born chemist and founder of the Australasian Association for the Advancement of Science (Macleod, 2013). It was stated (Figure 33) as collected from Tanna Island, New Hebrides, South Pacific by Prof. Archibald Liversidge pre-1927. However, Liversidge kept no diary of his travels (Macleod, personal communication) and although he visited Fiji (Kadavu) in 1876 and Fiji again in 1886 (Macleod, 2013), it is not clear that he ever visited Tanna Island himself. However, he does acknowledge (Liversidge, 1886) Commodore J. G. Goodenough R.N., C.B., C.M.G., (Goodenough, 1876) for other samples collected from Tanna in April 1875, and it is possible that this is the original collection date and that Goodenough was the collector, not Liversidge. A sample of brown/orange amber-like material (Natural History Museum code ZD.1996.7) re-coded by ourselves as NHM1 (Figure 33), was analysed on $25^{\text {th }}$ July 2016 and the days following, by FTIR and after derivatisation, by GCMS.
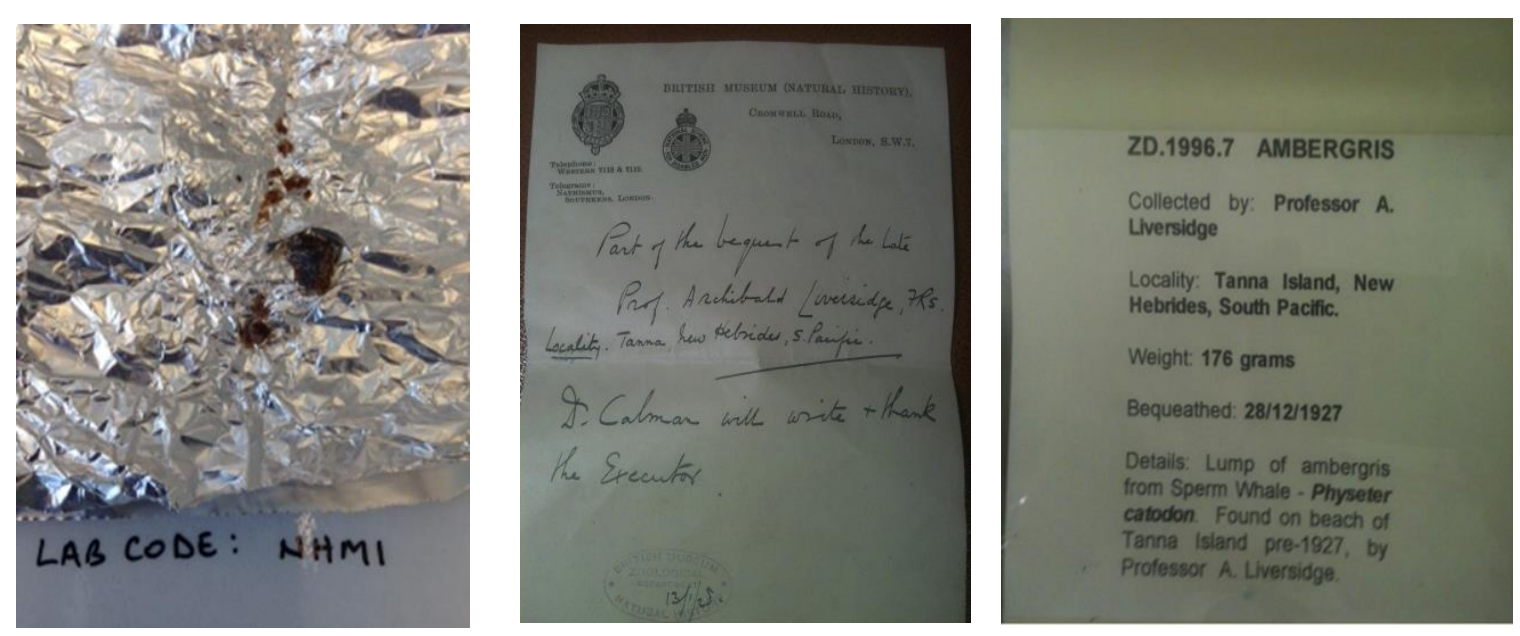

Figure 33. Photograph of sample supplied as ambergris collected by Prof Liversidge and photographs of documentation. 


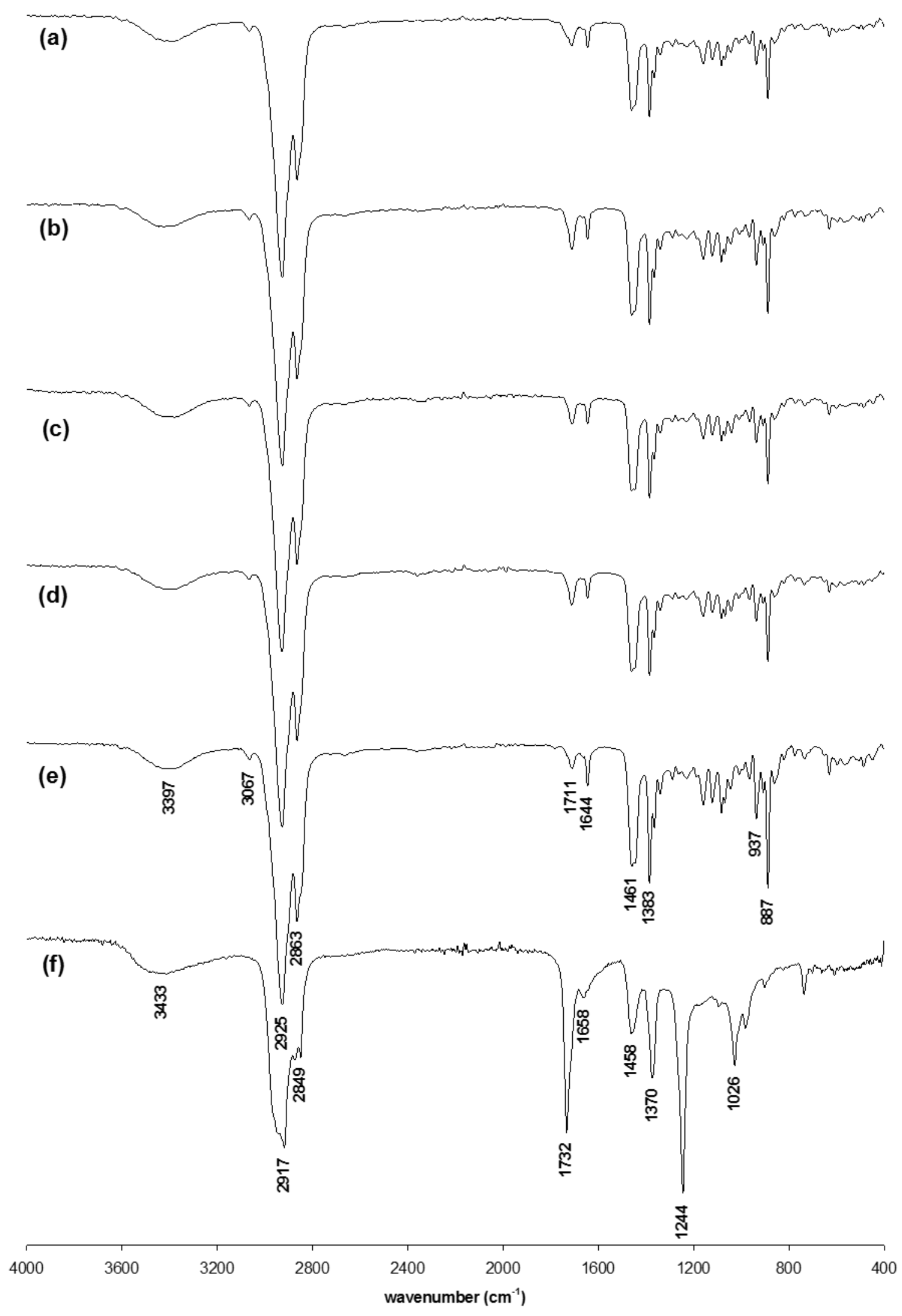

Figure 34. FTIR spectra of authenticated ambergris extracts (a-e) and Liversidge NHM1 putative ambergris sample (f). The latter is not ambergris. 
The FTIR spectrum (Figure 34) was inconsistent with ambergris and indicated the presence of esters of carboxylic acids. Consistent with the FTIR results, mass spectra of the two major components (Figures 34 and 35) suggested they were isomers of amyrin acetates and thus that the sample was possibly 'copal' or similar wood resin (and somewhat similar to the aforementioned samples from Walpole beach, WA. (cf Figures 32 and 34)). A form of fossilised copal is amber: thus the curation and classification of this sample as 'ambergris' may have been a result of a simple etymological confusion of 'amber' with 'ambergris'.

\section{It was concluded that this sample was a type of wood resin.}

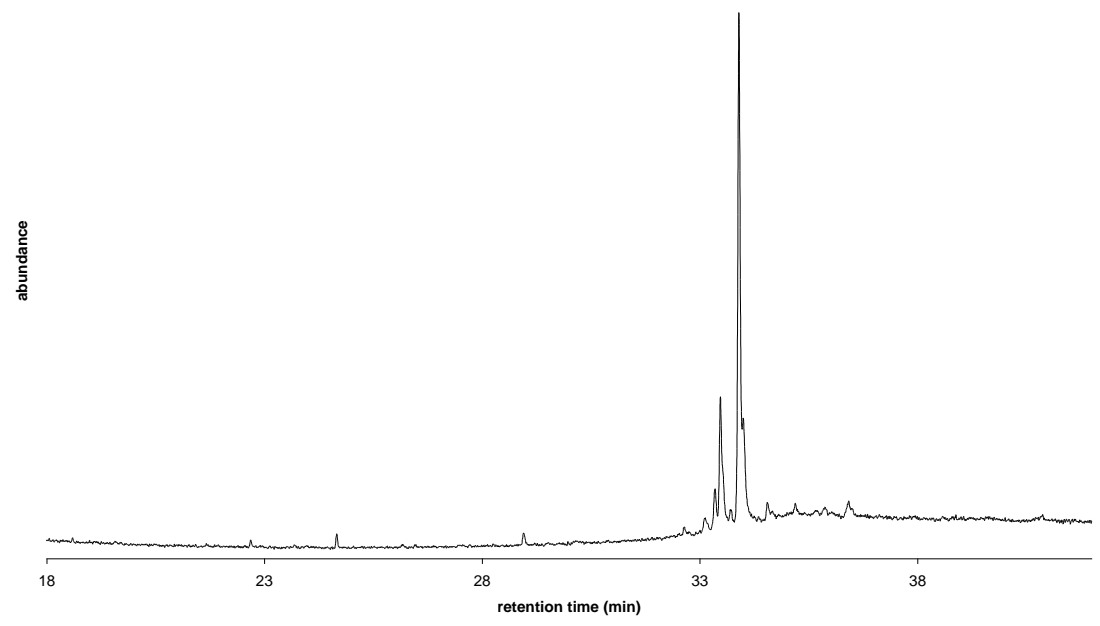

Figure 34. GCMS total ion current chromatogram of derivatised Liversidge NHM1 putative ambergris sample. The latter is not ambergris. Ambrein TMS ether had a retention time of about 30 minutes under these conditions. 

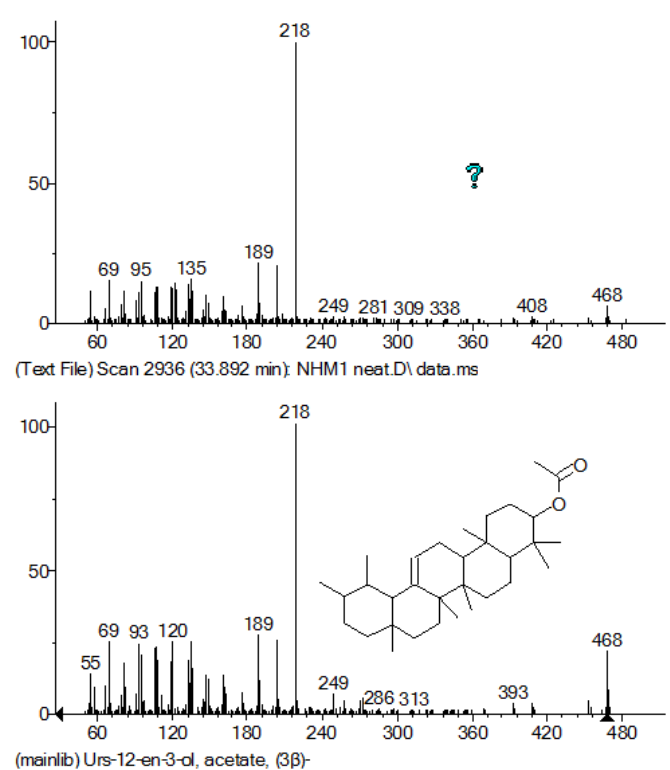

Figure 35. Mass spectrum of one of two major components of extract of derivatised NHM1 (upper) \& library spectrum (lower). Spectra are indicative of alpha and/or beta amyrin acetates.

\section{Conclusions}

Analysis of samples of jetsam from various beaches around the world herein indicated that they can be readily differentiated from jetsam ambergris by FTIR and GCMS analysis. Samples which were inconsistent with ambergris were often paraffin waxes or palm and related oils in various states of degradation. HTGC and HTGCMS facilitated identification of those samples which contained at least some undegraded intact triglycerides. Such materials are well-known pollutants of beaches. In addition, a number of jetsam samples proved to be higher plant resins. Some of these were probably related to amber. Some jetsam material may have odours somewhat resembling ambergris (which is due to the presence of ambroxan, ambrinol and related compounds; Rowland and Sutton 2017 and references therein)- possibly because some higher plant triterpenoids may degrade to form labdane-type derivatives with similar odours.

\section{Acknowledgements}

We are grateful to all the collectors and suppliers of jetsam named herein and to Professor R. Macleod for informative discussions about the life and work of Professor A. Liversidge FRS. 
We are grateful to Dr Richard Sabin Curator of Cetaceans at the Natural History Museum, London, U.K. for the sample of 'ambergris' purportedly collected by Liversidge and for valuable discussions. 


\section{References}

BBC 2013a-c. Available at http://www.bbc.co.uk/news/uk-england-22166777;

http://www.bbc.co.uk/news/uk-england-21350625; http://www.bbc.co.uk/news/uk-england24617697.

Dauqan, E.M.A., Sani, H.A., Aminah, A. and Kasim, Z.M. 2011. Fatty acids composition of four different vegetable oils (red palm olein, palm olein, corn oil and coconut oil) by gas chromatography. 2011 2nd International Conference on Chemistry and Chemical Engineering, IPCBEE 14, 31 - 34.

Goodenough, V. 1876. Journal of Commodore Goodenough, during his last command as senior officer on the Australian station, 1873-1875. H.S. King \& Co., London.

Liversidge, A. 1886. On the composition of some pumice and lava from the Pacific. Journal of the Royal Society of New South Wales, 20, 236.

Macleod, R. 2013. Archibald Liversidge, FRS. Imperial science under the Southern Cross. Royal Society of New South Wales, in association with Sydney University Press, 656pp.

Rowland, S.J. and Sutton, P.A. 2017. Chromatographic and spectral studies of jetsam and archived ambergris. Natural Product Research 31, 1752-1757. [doi:

10.1080/14786419.2017.1290618].

Sutton P.A. and Rowland S.J. 2012. High temperature gas chromatography-time-of-flightmass spectrometry (HTGC-ToF-MS) for high-boiling compounds. Journal of Chromatography A. 1243, 69-80. [doi: 10.1016/j.chroma.2012.04.044]. 